MARIANA YUKARI HAYASAKI PORSANI

OBESIDADE CANINA: UM ESTUDO DE PREVALÊNCIA NO MUNICÍPIO DE SÃO PAULO - SP

São Paulo

2019 


\section{Obesidade canina: um estudo de prevalência no município de São Paulo - SP}

Tese apresentada ao Programa de PósGraduação em Clínica Veterinária da Faculdade de Medicina Veterinária e Zootecnia da Universidade de São Paulo para a obtenção do título de Doutor em Ciências

\section{Departamento:}

Clínica Médica

\section{Área de concentração:}

Área de Concentração Clínica Veterinária

Orientador:

Prof. Dr. Marcio Antonio Brunetto

São Paulo

2019 
Autorizo a reprodução parcial ou total desta obra, para fins acadêmicos, desde que citada a fonte.

\section{DADOS INTERNACIONAIS DE CATALOGAÇÃO NA PUBLICAÇÃO}

(Biblioteca Virginie Buff D’Ápice da Faculdade de Medicina Veterinária e Zootecnia da Universidade de São Paulo)

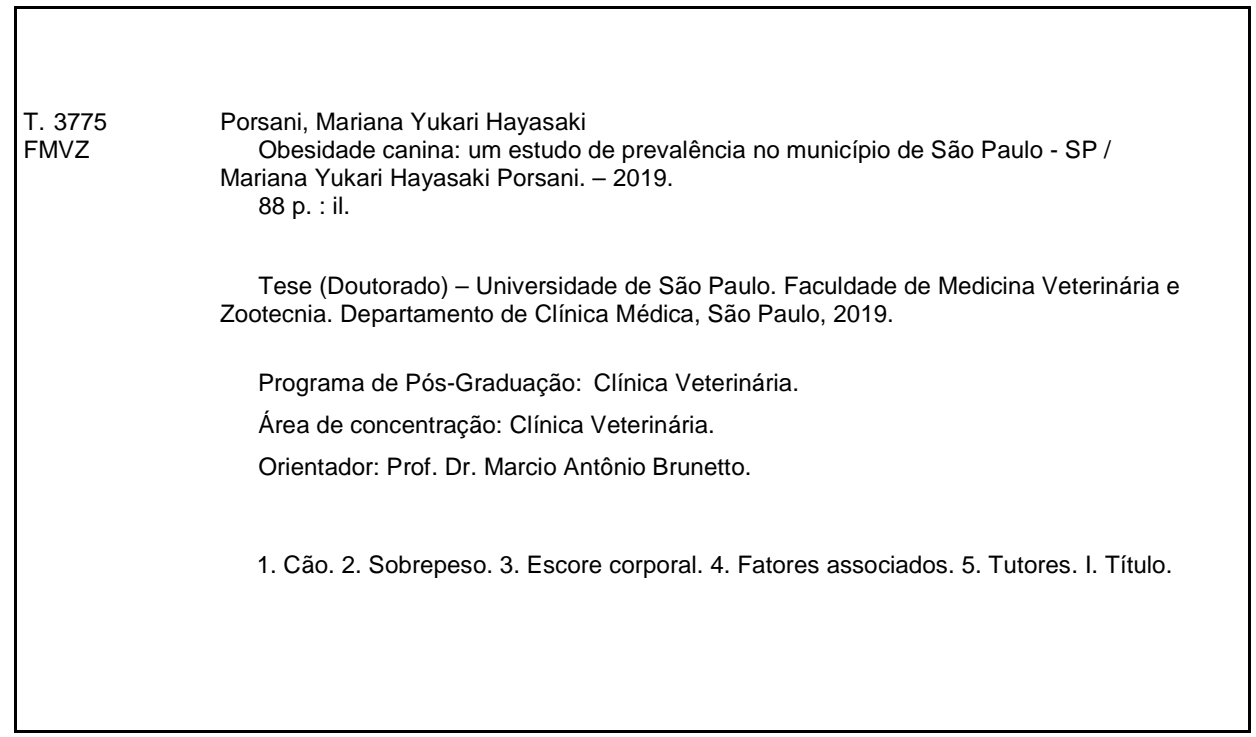

Ficha catalográfica elaborada pela bibliotecária Maria Aparecida Laet, CRB 5673-8, da FMVZ/USP. 


\section{CERTIFICADO}

Certificamos que a proposta intitulada "OBESIDADE CANINA: UM ESTUDO DE PREVALÊNCIA NO MUNICÍPIO DE SÃO PAULO - SP ", protocolada sob o CEUA no 3443010217, sob a responsabilidade de Márcio Antônio Brunetto e equipe; Marianayukari Hayasaki Porsani - que envolve a produção, manutenção e/ou utilização de animais pertencentes ao filo Chordata, subfilo Vertebrata (exceto o homem), para fins de pesquisa científica ou ensino - está de acordo com os preceitos da Lei 11.794 de 8 de outubro de 2008, com - Decreto 6.899 de 15 de julho de 2009, bem como com as normas editadas pelo Conselho Nacional de Controle da Experimentação Animal (CONCEA), e foi aprovada pela Comissão de Ética no Uso de Animais da Faculdade de Medicina Veterinária e Zootecnia da Universidade de São Paulo (CEUA/FMVZ) na reunião de 06/12/2017.

We certify that the proposal "Prevalence of canine obesity in São Paulo - SP ", utilizing 396 Dogs (males and females), protocol number CEUA 3443010217, under the responsibility of Márcio Antônio Brunetto and team; Marianayukari Hayasaki Porsani which involves the production, maintenance and/or use of animals belonging to the phylum Chordata, subphylum Vertebrata (except human beings), for scientific research purposes or teaching - is in accordance with Law 11.794 of October 8, 2008, Decree 6899 of July 15, 2009, as well as with the rules issued by the National Council for Control of Animal Experimentation (CONCEA), and was approved by the Ethic Committee on Animal Use of the School of Veterinary Medicine and Animal Science (University of São Paulo) (CEUA/FMVZ) in the meeting of 12/06/2017.

Finalidade da Proposta: Pesquisa

Vigência da Proposta: de 03/2017 a 11/2017 Área: Clínica Médica Veterinária

Origem: $\quad$ Animais de proprietários

Espécie: Cães sexo: Machos e Fêmeas idade: 1 a 20 anos $\quad$ N: 396

Linhagem: Variadas

Peso: 1 a $100 \mathrm{~kg}$

Resumo: A obesidade é a doença nutricional mais frequentemente em cães, caracterizada pelo acúmulo excessivo de gordura em toda extensão corporal.Inúmeras consequências estão associadas a este distúrbio, tais como alterações respiratórias, dermatológicas, distúrbios do aparelho locomotor, resistência insulínica e hiperlipidemia. Estas, se não controladas, resultam na redução da qualidade e sobrevida do animal. A condição corporal dos cães sofreinfluênciadireta do estilo de vida de seus tutores, isto devido a transferência aos pets dos hábitosalimentares errôneos associados aosedentarismo.Escassos são os estudos epidemiológicos com a caracterização destacondição em cães na América Latina, o que dificulta a implementação de medidas profiláticas no controle e prevenção da obesidade canina. Dessa forma, objetiva-se com este estudo quantificar e caracterizar a população canina obesa do município de São Paulo (SP).Além disso, pretende-se determinar aspectos nutricionais e ambientais envolvidos na origem desta afecção. Serão visitados domicílios no município de São Paulo sorteados de forma aletória com base em fórmula matemática de prevalência esperada, através de um sorteio aleatório das malhas dos setores censitários classificados em 2010 (IBGE).Os cães serão avaliados e classificados através do escore de condição corporalna escala de 9 pontos, mensurações morfométricas e escore de massa muscular. A condição corporal dos tutores será realizada através do cálculo do índice de massa corporal e medidas morfométricas. Os tutores irão responder questionários baseados na condição socioeconômica assim como seus hábitos e preferências. Os resultados serão analisados por meio de estatística descritiva, análise multivariada e teste de correlação de Spearman, de acordo com a variável e normalidade dos dados obtidos.

Local do experimento: Na casa dos proprietários ou triagem do hospital veterinário da FMVZ USP

São Paulo, 22 de dezembro de 2017

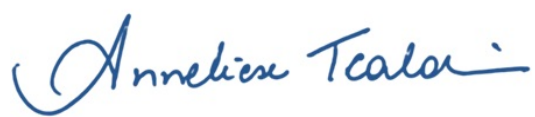

Profa. Dra. Anneliese de Souza Trald

Presidente da Comissão de Ética no Uso de Animais

Faculdade de Medicina Veterinária e Zootecnia da Universidade Faculdade de Medicina Veterinária e Zootecnia da Universidade de São Paulo

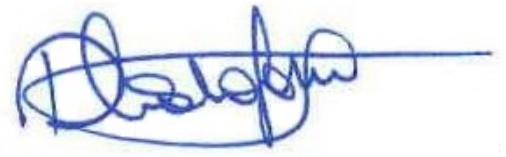

Roseli da Costa Gomes

Secretária Executiva de São Paulo 


\section{USP - ESCOLA SUPERIOR DE \\ AGRICULTURA "LUIZ DE \\ QUEIROZ" DA UNIVERSIDADE}

\section{PARECER CONSUBSTANCIADO DO CEP}

\section{DADOS DO PROJETO DE PESQUISA}

Título da Pesquisa: OBESIDADE CANINA: UM ESTUDO DE PREVALÊNCIA NO MUNICÍPIO DE SÃO PAULO - SP

Pesquisador: MARCIO ANTONIO BRUNETTO

Área Temática:

Versão: 3

CAAE: 71711317.2 .0000 .5395

Instituição Proponente: UNIVERSIDADE DE SAO PAULO

Patrocinador Principal: Financiamento Próprio

\section{DADOS DO PARECER}

Número do Parecer: 2.362.288

\section{Apresentação do Projeto:}

A obesidade canina é considerada uma pandemia mundial de rápido crescimento que pode culminar para a perda da qualidade de vida e redução da longevidade. A rotina muitas vezes sedentária e os hábitos alimentares dos tutores influenciam diretamente nos hábitos dos animais e consequentemente na sua condição corporal. O comportamento antropomórfico dos tutores, no qual relacionam-se o alimento como forma de interação e demonstração de afeto em conjunto ao comportamento de mendicância dos cães contribuem para o fornecimento excessivo de alimento o que traz como consequência o quadro de obesidade.

Até o presente momento, a escassez de informações referentes a epidemiologia atual da obesidade canina na América Latina despertam questionamentos em relação a quantificação e caracterização desta enfermidade. No qual se faz necessária a caracterização atual da real população de cães obesos e seus tutores na cidade de São Paulo, para se propor novas estratégias de prevenção e controle desta doença.

\section{Objetivo da Pesquisa:}

Estimar a prevalência e perfil da obesidade na população de cães domiciliados na cidade de São Paulo SP.

Objetivos específicos

Determinar os aspectos nutricionais e ambientais envolvidos no desenvolvimento da obesidade

Endereço: Avenida Pádua Dias,11 Caixa Postal 9

Bairro: São Dimas

UF: SP

Município: PIRACICABA

CEP: $13.418-900$

Telefone: (19)3429-4400

E-mail: cep.esalq@usp.br 


\section{USP - ESCOLA SUPERIOR DE AGRICULTURA "LUIZ DE QUEIROZ" DA UNIVERSIDADE}

Continuação do Parecer: 2.362.288

canina; -

Definir em qual faixa etária a obesidade é mais frequente;

-Determinar a possível correlação entre o índice de massa corporal dos tutores com o escore de condição corporal e medidas morfometrias dos cães;

-Avaliar a percepção dos tutores em relação ao escore de condição corporal dos cães e à obesidade;

- Observar a frequência da obesidade e sua relação com sexo, castração e raça;

- Comparar a prevalência da obesidade canina em cães atendidos na rotina do Serviço de Clínica Médica, Cirurgia e Dermatologia do Hospital Veterinário da Faculdade de Medicina Veterinária e Zootecnia da Universidade de São Paulo (HOVET/FMVZ-USP) com os animais avaliados nos domicílios;

- Observar se o bem-estar destes animais está comprometido pela obesidade

\section{Avaliação dos Riscos e Benefícios:}

Os riscos associados à pesquisa são dirimidos com o TCLE e com os métodos utilizados para a realização da pesquisa que estão descritos no projeto.

\section{Comentários e Considerações sobre a Pesquisa:}

A pesquisa se apresenta com uma promissora ferramenta para o desenvolvimento de novas estratégias de prevenção e controle para a obesidade canina.

\section{Considerações sobre os Termos de apresentação obrigatória:}

Os documentos obrigatórios estão presentes e são adequados.

\section{Recomendações:}

Pendência 1) (Atendida) Escanear novamente a folha de rosto, pois está inelegível. Corrigir o número de voluntários.

Pendência 2) (Atendida) Rever a declaração da instituição, pois a ESALQ não tem a responsabilidade sobre a infraestrutura

necessária para o desenvolvimento da pesquisa. Isso cabe a USP-Pirassununga.

Pendência 3) (Atendida) TCLE deve conter os dados de endereço e telefone do CEP-ESALQ. O mesmo deve ser rubricado e assinado em todas as páginas, sendo uma via entregue ao voluntário e outra será arquivada pelos pesquisadores

Pendência 4) (Atendida) Os dados completos (como endereço, sexo, data de nascimento, etc) de identificação tanto do proprietário quanto do animal faz parte do questionário e não do TCLE.

Endereço: Avenida Pádua Dias, 11 Caixa Postal 9

Bairro: São Dimas

UF: SP Município: PIRACICABA

CEP: $13.418-900$

Telefone: (19)3429-4400

E-mail: cep.esalq@usp.br 


\section{USP - ESCOLA SUPERIOR DE AGRICULTURA "LUIZ DE QUEIROZ" DA UNIVERSIDADE}

Continuação do Parecer: 2.362.288

Pendência 5) (Atendida) Colocar o DDD do telefone descrito na Garantia de Acesso no TCLE.

Pendência 6) (Atendida) Colocar o significado da sigla CEUAVET no TCLE.

Pendência 7) (Atendida) Trocar o comitê de ética da FMVZ/USP na página 9 do projeto pelo Comitê de ética da ESALQ.

Pendência 8) (Atendida) O questionário não foi apresentado no projeto mesmo sendo citado na página 10 como apêndice.

Pendência 9) (Atendida) Deixar mais claro no tópico Direito de confidencialidade do TCLE que a identidade, assim como as suas informações pessoais, do dono do animal também serão mantidas sobre sigilo.

\section{Conclusões ou Pendências e Lista de Inadequações:}

Todas as pendências foram atendidas.

\section{Considerações Finais a critério do CEP:}

Após a aprovação do projeto, os pesquisadores devem atentar para a necessidade de envio de relatórios parciais (no mínimo um a cada 12 meses) ou final (ao término da pesquisa). Destaca-se que o parecer consubstanciado é o documento oficial de aprovação do sistema CEP/CONEP.

Intercorrências ou eventos adversos devem ser relatados ao CEP por meio da PB. Eventuais mudanças pretendidas no protocolo devem ser comunicadas como emendas ao CEP por meio da PB.

Este parecer foi elaborado baseado nos documentos abaixo relacionados:

\begin{tabular}{|c|c|c|c|c|}
\hline Tipo Documento & Arquivo & Postagem & Autor & Situação \\
\hline $\begin{array}{l}\text { TCLE / Termos de } \\
\text { Assentimento / } \\
\text { Justificativa de } \\
\text { Ausência }\end{array}$ & TCLE2Mariana.pdf & $\begin{array}{c}\text { 31/10/2017 } \\
22: 33: 22\end{array}$ & $\begin{array}{l}\text { Sandra Helena da } \\
\text { Cruz }\end{array}$ & Aceito \\
\hline $\begin{array}{l}\text { Informações Básicas } \\
\text { do Projeto }\end{array}$ & $\begin{array}{l}\text { PB_INFORMAÇŌES_BÁSICAS_DO_P } \\
\text { ROJETO 902001.pdf }\end{array}$ & $\begin{array}{l}11 / 10 / 2017 \\
16: 20: 07\end{array}$ & & Aceito \\
\hline Outros & $\begin{array}{l}\text { MemoPlataformaBrasilCARTAJUSTIFIC } \\
\text { ATIVA.pdf }\end{array}$ & $\begin{array}{c}11 / 10 / 2017 \\
16: 19: 18\end{array}$ & $\begin{array}{l}\text { MARCIO ANTONIO } \\
\text { BRUNETTO }\end{array}$ & Aceito \\
\hline Folha de Rosto & Folha_de_Rosto.pdf & $\begin{array}{c}11 / 10 / 2017 \\
16: 00: 25\end{array}$ & $\begin{array}{l}\text { MARCIO ANTONIO } \\
\text { BRUNETTO }\end{array}$ & Aceito \\
\hline $\begin{array}{l}\text { Projeto Detalhado / } \\
\text { Brochura } \\
\text { Investigador }\end{array}$ & ProjetoObesosplataformaBrasil.pdf & $\begin{array}{c}10 / 10 / 2017 \\
14: 41: 45\end{array}$ & $\begin{array}{l}\text { MARCIO ANTONIO } \\
\text { BRUNETTO }\end{array}$ & Aceito \\
\hline
\end{tabular}

Endereço: Avenida Pádua Dias,11 Caixa Postal 9

Bairro: São Dimas

UF: SP Município: PIRACICABA

CEP: $13.418-900$

Telefone: (19)3429-4400

E-mail: cep.esalq@usp.br 


\section{USP - ESCOLA SUPERIOR DE AGRICULTURA "LUIZ DE QUEIROZ" DA UNIVERSIDADE}

Continuação do Parecer: 2.362.288

\begin{tabular}{|c|c|c|c|c|}
\hline $\begin{array}{l}\text { TCLE / Termos de } \\
\text { Assentimento / } \\
\text { Justificativa de } \\
\text { Ausência }\end{array}$ & TCLE_plataforma_Brasil.pdf & $\begin{array}{c}\text { 10/10/2017 } \\
14: 26: 04\end{array}$ & $\begin{array}{l}\text { MARCIO ANTONIO } \\
\text { BRUNETTO }\end{array}$ & Aceito \\
\hline $\begin{array}{l}\text { Declaração de } \\
\text { Instituição e } \\
\text { Infraestrutura } \\
\end{array}$ & Declaracao_instituicao.pdf & $\begin{array}{c}\text { 10/10/2017 } \\
14: 09: 06\end{array}$ & $\begin{array}{l}\text { MARCIO ANTONIO } \\
\text { BRUNETTO }\end{array}$ & Aceito \\
\hline $\begin{array}{l}\text { Declaração de } \\
\text { Pesquisadores }\end{array}$ & Declaracaopesquisador.pdf & $\begin{array}{c}20 / 09 / 2017 \\
10: 56: 45 \\
\end{array}$ & $\begin{array}{l}\text { MARCIO ANTONIO } \\
\text { BRUNETTO }\end{array}$ & Aceito \\
\hline Outros & encaminhamento.pdf & $\begin{array}{c}14 / 06 / 2017 \\
15: 00: 36 \\
\end{array}$ & $\begin{array}{l}\text { MARCIO ANTONIO } \\
\text { BRUNETTO } \\
\end{array}$ & Aceito \\
\hline Outros & infraestrutura.pdf & $\begin{array}{c}14 / 06 / 2017 \\
14: 53: 31 \\
\end{array}$ & $\begin{array}{l}\text { MARCIO ANTONIO } \\
\text { BRUNETTO } \\
\end{array}$ & Aceito \\
\hline Outros & sujeito.pdf & $\begin{array}{c}14 / 06 / 2017 \\
14: 51: 42\end{array}$ & $\begin{array}{l}\text { MARCIO ANTONIO } \\
\text { BRUNETTO }\end{array}$ & Aceito \\
\hline Outros & MarianaPorsani.pdf & $\begin{array}{c}14 / 06 / 2017 \\
14: 50: 28 \\
\end{array}$ & $\begin{array}{l}\text { MARCIO ANTONIO } \\
\text { BRUNETTO } \\
\end{array}$ & Aceito \\
\hline Orçamento & orcamento.pdf & $\begin{array}{c}14 / 06 / 2017 \\
14: 42: 40 \\
\end{array}$ & $\begin{array}{l}\text { MARCIO ANTONIO } \\
\text { BRUNETTO } \\
\end{array}$ & Aceito \\
\hline
\end{tabular}

Situação do Parecer:

Aprovado

Necessita Apreciação da CONEP:

Não

PIRACICABA, 01 de Novembro de 2017

\section{Assinado por: \\ Sandra Helena da Cruz \\ (Coordenador)}

Endereço: Avenida Pádua Dias, 11 Caixa Postal 9

Bairro: São Dimas

UF: SP

Município: PIRACICABA

CEP: $13.418-900$

Telefone: (19)3429-4400

E-mail: cep.esalq@usp.br 
Autor: PORSANI, M.Y.H

Obesidade canina: Um estudo de prevalência no município de São Paulo - SP

Tese apresentada ao Programa de PósGraduação em Clínica Veterinária da Faculdade de Medicina Veterinária e Zootecnia da Universidade de São Paulo para a obtenção do título de Doutor em Ciências.

Data:

\section{Banca Examinadora}

Prof. Dr.

Instituição: Julgamento:

Prof. Dr. Instituição: Julgamento:

Prof. Dr. Instituição: Julgamento:

Prof. Dr. Instituição: Julgamento:

Prof. Dr. Instituição: Julgamento: 


\section{AGRADECIMENTOS}

Gostaria de agradecer as pessoas que estiveram presentes, em toda essa minha caminhada até aqui e que me auxiliaram para que tudo fosse possível.

A minha família, por me apoiar desde a infância, quando escolhi ser médica veterinária me dando todo o apoio e suporte.

Minha mãe, em especial por estar presente em todas as escolhas, questionamentos e medos, sem você tudo seria mais difícil....

Agradeço aos meus amigos que sempre torceram por mim e estiveram comigo em todos os momentos. Camila, Paula, Déa e Pamela, obrigada por terem me ouvido sempre.

Ao meu noivo Leandro pela compreensão, apoio, carinho e amor no último ano do doutorado.

Agradeço aos presentes que a USP me deu: Marcio, Fabio, Brana, Vivian, Fernanda, Andressa e Vinicius. Aprendi muito com vocês sobre a medicina veterinária e a vida.

Aos amigos da salinha por deixarem meus dias mais leves e engraçados, Naty, Amanda, Caio, Cecília e Fernando.

Aos Professores da FMVZ-USP por todos os ensinamentos.

Obrigada às pessoas que ajudaram na confecção desse estudo: Professor Marcio Brunetto, Professor Ricardo Dias, Camila Marinelli, Fabio Teixeira, Yara Arakaki, Vinicius Vasques, Gabriel Siqueira e à equipe da Royal Canin, Cintia e Carolina. O presente trabalho foi realizado com apoio da Coordenação de Aperfeiçoamento de Pessoal de Nível Superior - Brasil (CAPES) - Código de Financiamento 001.

Agradecimento especial aos tutores de cães que foram muito gentis e aceitaram participar do estudo. Vocês me ensinaram muito sobre humildade, respeito e compaixão. 
"O que sabemos é uma gota; o que ignoramos é um oceano." Isaac Newton 


\section{RESUMO}

PORSANI, M. Y. H. Obesidade canina: Um estudo de prevalência no município de São Paulo - SP [Canine obesity: a prevalence study in the city of São Paulo]. 2019. $88 \mathrm{f}$. Tese (Doutorado em Ciências) - Faculdade de Medicina Veterinária e Zootecnia, Universidade de São Paulo, São Paulo, 2019.

A obesidade é caracterizada pelo acúmulo excessivo de gordura corporal que pode resultar na redução da qualidade e expectativa de vida. Estudos epidemiológicos que caracterizaram a obesidade canina na América Latina são escassos. Dessa forma, os objetivos deste trabalho foram determinar a prevalência da obesidade canina no município de São Paulo e os fatores a ela associados. Foram realizadas visitas a domicílios da cidade, escolhidos segundo o censo dos cães domiciliados de São Paulo e cálculo de prevalência de obesidade esperada. Os cães tiveram seu escore de condição corporal (ECC) avaliados e os tutores o índice de massa corporal (IMC) e medidas morfométricas. Além de informações referentes a condição socioeconômica e estilo de vida obtidas por meio de questionário. Para a análise estatística, procedeuse a estimativa da prevalência da obesidade, teste de qui-quadrado, análise de correspondência múltipla e regressão logística múltipla. De acordo com a avaliação de 285 cães de 221 tutores determinou-se a prevalência de obesidade dos cães domiciliados no município de São Paulo- SP em 14,6\%. Houve associação do ECC dos cães com sexo $(p=0,003)$ e status reprodutivo $(p<0,001)$, sendo que a maioria dos animais acima do peso eram do sexo feminino e, castrados, independente do sexo. Em relação aos cuidados com os pets, houve associação do ECC com a frequência com que os animais eram assistidos por médico veterinário $(p=0,026)$. Essa associação também foi encontrada em relação a frequência alimentar $(p=0,033)$ e consumo de petiscos $(p=0,011)$. Sobre fatores inerentes aos tutores houve associação dos hábitos alimentares em relação ao consumo de guloseimas $(p=0,005)$ e a presença de moradores idosos. A prevalência da obesidade canina observada nesse estudo foi semelhante à observada em outras cidades do mundo, assim como os fatores associados.

Palavras-chave: Cão. Sobrepeso. Escore corporal. Fatores associados. Tutores 


\begin{abstract}
PORSANI, M. Y. H. Canine obesity: a prevalence study in the city of Sao Paulo. 2019. 88 f. Tese (Doutorado em Ciências) - Faculdade de Medicina Veterinária e Zootecnia, Universidade de São Paulo, São Paulo, 2019.

Obesity can be characterized by excessive accumulation of body fat that can result in a reduce in both quality and life expectancy. Epidemiological studies in Latin America that characterize canine obesity are scares. With that in mind, the objective of this work is to determine the prevalence of canine obesity in the city of Sao Paulo and all the factors associated to it. Houses where selected according to the census of domiciled dogs of Sao Paulo, and visits were made where the calculation of the prevalence of expected obesity was based. The dogs had their body condition score (BCS) evaluated and the owners had body mass index (BMI) and morphometric measures. In addition to information regarding socioeconomic status and lifestyle obtained through a questionnaire. For the statistical analysis, the prevalence of obesity, chi-square test, multiple correspondence analysis and also the multiple logistic regression were estimated. According to the evaluation of 285 dogs that belong to 221 owners the prevalence of obesity of dogs domiciled in the city of São Paulo-SP was determined in $14.6 \%$. There was an association between BCS of dogs with gender $(p=0.003)$ and reproductive status ( $p<0.001$ ), with the majority of overweight animals being female and castrated regardless of gender. In regard to the pet care, the BCS was associated with the frequency with which the animals were assisted by a veterinarian $(p=0.026)$. This association was also found in relation to food frequency $(p=0.033)$ and snack consumption ( $p=0.011$ ). As for factors inherent to owners, there was an association between eating habits in relation to the consumption of treats $(p=0.005)$ and the presence of elderly residents. The prevalence of canine obesity observed in this study was similar to that observed in other cities of the world, as well as the associated factors.
\end{abstract}

Key words: Dog. Overweight. Body condition score. Associated factors. Owners 


\section{LISTA DE TABELAS}

Tabela 1 - Compilado de estudos que investigaram a prevalência de obesidade em cães

Tabela 2 - Locais abordados no estudo e motivos de exclusão. São Paulo - 44 SP, 2019...

Tabela 3 - Prevalência da condição corporal dos 285 cães avaliados no estudo. São Paulo - SP, 2019

Tabela 4 - Prevalência dos animais em sobrepeso e obesos avaliados no estudo em diversas características. São Paulo - SP, 2019

Tabela 5 - Distribuição das características dos 285 cães avaliados, segundo a classificação da condição corporal. São Paulo - SP, 2019.

Tabela 6 - Manejo sanitário e nutricional realizados pelos tutores dos 285 cães avaliados no estudo, distribuídos segundo a classificação da condição corporal. São Paulo - SP, 2019.

Tabela 7 - Distribuição das características socioeconômicas dos tutores entrevistados, distribuídos segundo a classificação da condição corporal dos cães. São Paulo - SP, 2019.

Tabela 8 - Distribuição das características do perfil nutricional e atividade física dos tutores entrevistados, segundo a classificação da condição corporal dos cães. São Paulo - SP, 2019.

Tabela 9 - Distribuição das características dos tutores entrevistados, segundo a classificação da condição corporal dos cães. São Paulo - SP, 2019.

Tabela 10 - Distribuição das informações sobre os moradores dos domicílios avaliados, segundo a classificação da condição corporal dos cães. São Paulo - SP, 2019

Tabela 11 - Classificação do escore de condição corporal atribuído pelo tutor do animal com base no questionário respondido. São Paulo - SP, 2019.

Tabela 12 - Análise de regressão logística múltipla dos animais avaliados no estudo, divididos em categorias de condição corporal. São Paulo - SP, 2019.

Tabela 13 - Análise de regressão logística múltipla de cães em sobrepeso e obesos. São Paulo - SP, 2019. 


\section{LISTA DE FIGURAS}

Figura 1 - Análise de correspondência múltipla da relação entre a classificação do escore de condição corporal (ECC) dos cães e caraterísticas significativas na análise simples. São Paulo - SP, 2019.

Figura 2 - Análise de correspondência múltipla da relação entre a classificação do escore de condição corporal (ECC) com as variáveis significativas em relação ao tutor na análise simples. São Paulo - SP, 2019 


\section{LISTA DE QUADROS}

Quadro 1 - $\quad$ Definição do primeiro domicílio a ser visitado e o intervalo seguido......... 36

Quadro 2 - Classificação das faixas etárias caninas, segundo o porte corporal. Adaptado de Hosgood; Scholl (1998)............................................. 38

Quadro 3 - Classificação da intensidade de atividade física semanal dos cães avaliados no estudo. Adaptado de Degeling; Lindsay; Mccormack (2012)

Quadro 4 - Classificação da intensidade da atividade física diária dos cães. Adaptado de Degeling; Lindsay; Mccormack (2012) ..........................

Quadro 5 - Valores de referência da relação cintura/quadril, baseado em gênero e idade. Adaptado de Lin et al. (2002) e Huang et al. (2002).................... 40

Quadro 6 - Classificação dos hábitos alimentares. Adaptado de Ministério da

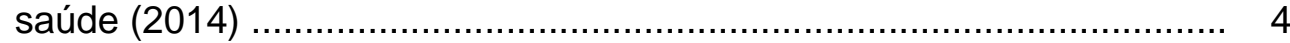

Quadro 7 - $\quad$ Classificação da renda domiciliar. Adaptado de Neri (2018)................... 41 


\section{SUMÁRIO}

INTRODUÇÃO ....................................................................................... 18

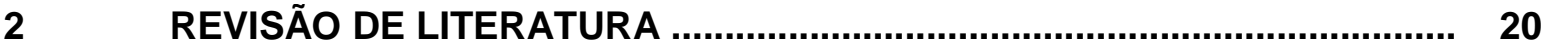

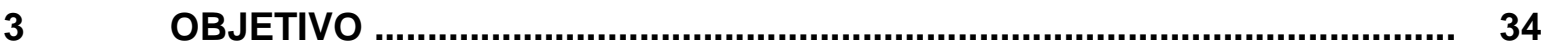

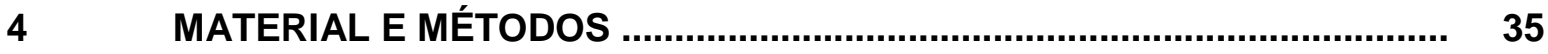

4.1 Seleção dos domicílios ................................................................ 35

4.2 Avaliação dos cães ........................................................................ 37

4.2.1 Condição corporal ...................................................................... 37

4.2.2 Porte do animal e faixa etária ..................................................... 38

4.2.3 Classificação da frequência de atividade física ................................... 39

4.3 Avaliação corporal dos tutores ............................................................. 39

4.3.1 Índice de massa corporal............................................................. 39

4.3.2 Variáveis antropométricas............................................................. 40

4.4 Questionário ................................................................................ 41

4.4.1 Classificação dos hábitos alimentares dos tutores ............................. 41

4.4.2 Classificação da classe social ..................................................... 41

4.5 Análise estatística .................................................................. 42

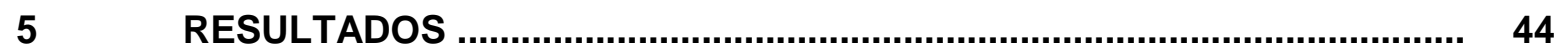

5.1 Análise de prevalência .............................................................. 44

5.2 Estatística descritiva e associação das características dos cães e dos tutores e manejo empregado aos animais.

5.3 Percepção do tutor frente ao escore de condição corporal do animal ...... 54

5.4 Análise de correspondência múltipla .................................................... 55

5.5 Análise de regressão logística múltipla .............................................. 57

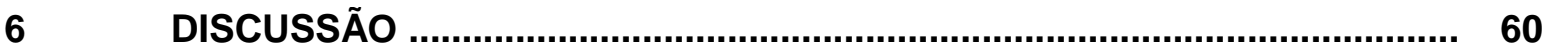

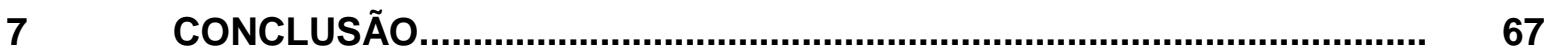

REFERÊNCIAS ........................................................................................ 68

APÊNDICES ...................................................................................... 85 


\section{INTRODUÇÃO}

A obesidade é a doença nutricional de maior incidência na clínica de pequenos animais (FREEMAN et al., 2006; PEÑA et al., 2008; GERMAN et al., 2010; MAO et al., 2013; ALONSO et al., 2017).

Esta doença provoca inúmeros malefícios à saúde sendo responsável por complicações que podem levar à redução da sobrevida (RYAN et al., 2010; BRUNETTO et al., 2011a; MAO et al., 2013; ALONSO et al., 2017). O excesso de gordura corporal é o resultado do desequilíbrio prolongado entre o consumo alimentar e o gasto energético (ZORAN, 2010; BROOKS et al., 2014). Essa situação de balanço energético positivo crônico pode estar relacionada a fatores genéticos, ambientais, comportamentais e socioculturais (MCGREEVY et al., 2005; LUND et al., 2006; APTEKMANN et al., 2013). Em cães, a castração e o avançar da idade estão associados à redução do metabolismo, mudanças na composição corporal e podem resultar em alterações no comportamento alimentar e menor estímulo para atividade física (ROBERTSON, 2003; GERMAN, 2006; COURCIER et al., 2010; ZORAN, 2010; GERMAN et al., 2012; KAWUASHI et al., 2017).

Existe também a influência dos tutores na gênese da obesidade, devido ao manejo empregado aos seus cães, como fornecimento excessivo de alimentos e a falta de atividade física. Isso porque em muitos casos os tutores estabelecem atitudes errôneas e, em inúmeras vezes fornecem alimento como forma de agrado e interação com o animal. Além de transferirem seus hábitos alimentares não saudáveis e o sedentarismo (BLAND et al., 2010; MUNOZ-PRIETO et al., 2018).

O diagnóstico preciso da condição corporal dos cães pode ser realizado pelo emprego da técnica de diluição de isótopos de deutério (BRUNETTO et al., 2011b) e de densitometria por dupla emissão de raios-X [DEXA - dual energy X-ray absorptiometry (MAWBY et al., 2004)]. Essas técnicas determinam as porcentagens de massa magra e gordura, mas apresentam alto custo e não são utilizadas na rotina clínica.

O método mais usual e de fácil aplicabilidade na prática clínica é a avaliação do escore de condição corporal (ECC), escala validada por Laflamme (1997). Este método consiste em inspecionar e palpar a gordura na região das costelas, abdômen, pescoço, cauda e em regiões de proeminências ósseas dos animais, que são locais de acúmulo de gordura (LAFLAMME, 1997; GERMAN, 2006; WITZEL et 
al., 2014). A escala numérica de classificação do ECC varia entre 1-9, na qual valores entre 1 a 3 representam cão abaixo do peso, 4 e 5 animal em condição ideal, 6 e 7 em sobrepeso e 8 e 9 obeso (LAFLAMME, 1997).

A estimativa da população de cães em sobrepeso e obeso já foi determinada em alguns países como Estados Unidos, Reino Unido, China, Japão e Espanha, cujos resultados demonstraram que 20-30\% dos cães apresentavam sobrepeso e 5 a 20\% obesidade (LUND et al., 2006; COURCIER et al., 2010; MAO et al., 2013; USUI; YASUDA; KOKETSU, 2016; ALONSO et al., 2017). Até o presente momento são escassas as informações referentes a epidemiologia da obesidade canina e o perfil dos tutores na América Latina. Dessa forma, a determinação e caracterização desta população se faz necessária para que, no futuro, novas estratégias de prevenção e controle sejam propostas. 


\section{REVISÃO DE LITERATURA}

\subsection{Epidemiologia da obesidade}

A incidência de obesidade em humanos tem aumentado de maneira expressiva em todo o mundo (MELDRUM; MORRIS; GAMBONE, 2017), segundo dados da Organização Mundial da Saúde (OMS) atualmente essa doença é considerada uma pandemia global. A população de seres humanos em sobrepeso é superior a 9,0 bilhões de adultos e, a de obesos chega a 650 milhões (GARVEY et al., 2016;WHO, 2017). Em crianças e adolescentes o número também é crescente: cerca de 340 milhões apresentaram esta condição no ano de 2016 (WHO, 2017). No Brasil, o Ministério da Saúde estimou que, em 2017, 51,0\% da população estava acima do peso ideal (Ministério da Saúde, 2017).

$\mathrm{Na}$ população canina, o aumento expressivo da prevalência de obesidade também foi evidenciado nas últimas décadas (Tabela 1), sendo a população de cães em sobrepeso e obesos correspondente a números que variaram de 30 a $50 \%$ (MCGREEVY et al., 2005; GERMAN, 2006; ZORAN, 2010; ALONSO et al., 2017). O primeiro estudo sobre o assunto foi realizado no ano de 1960, na Suécia, na qual foi descrito que $11,6 \%$ dos cães avaliados estavam em condição corporal acima da ideal. Nesse primeiro estudo epidemiológico foram avaliados prontuários de 10.993 cães submetidos à necropsia por um período de 27 anos (1930 a 1957). Os cães foram classificados como obesos de acordo com o acúmulo de gordura visualizado de forma macroscópica no corpo do animal (KROOK; LARSSON; ROONEY, 1960). Este tipo de análise não se equivale aos métodos atuais e é mais subjetivo, portanto esses dados podem ser imprecisos.

Nas décadas subsequentes, dois estudos prospectivos foram realizados no Reino Unido. O primeiro avaliou a população de cães atendidos em um hospital veterinário por um ano em 1970 e determinou por meio de palpação e avaliação visual que dos 1000 cães avaliados, 28,0\% estavam em sobrepeso e/ou obesos (MASON, 1970). O segundo estudo, realizado na década de 1980 por Edney; Smith (1986), avaliou por meio da mensuração do ECC na escala de 5 pontos a população de 8.268 cães em um período de seis meses e determinou que $21,4 \%$ estavam obesos e 2,9\% apresentavam sobrepeso. Uma estimativa superior ao encontrado nos demais estudos. 
Já nas décadas de 80 e 90, dois estudos foram conduzidos nos Estados Unidos. O primeiro foi realizado por Kronfeld; Donoghue; Glickman (1991), o qual avaliou o ECC na escala de 5 pontos de modo prospectivo da população de um hospital por três meses (março a junho de 1986) e classificou a população avaliada ( $n=3.729$ ) como $22,0 \%$ em sobrepeso e $0,9 \%$ como obesos.

O segundo estudo prospectivo foi realizado no ano de 1995, mas publicado apenas em 2006 e também avaliou informações sobre ECC na escala de 5 pontos, castração, idade e fatores relacionados à alimentação destes cães, atendidos em clínicas veterinárias nos Estados Unidos no período de um ano. Os resultados determinaram que de 21.754 animais - 29,0\% estavam em sobrepeso e 5,1\% eram obesos (LUND et al., 2006).

Na América Latina, há escassez de dados epidemiológicos sobre a obesidade em cães. O único estudo publicado até o momento foi também realizado na cidade de São Paulo e avaliou animais em clínicas veterinárias, hospitais, pet shops, parques e domicílios privados por um ano. Os tutores responderam um questionário com informações inerentes aos animais e, a avaliação da condição corporal dos cães e dos proprietários foram realizadas de forma visual pelo avaliador, sendo considerados obesos os animais e os tutores que apresentavam excesso de gordura corporal em regiões de depósitos visíveis. Neste estudo, dos 648 cães avaliados, 107 foram considerados obesos, equivalente a 16,5\% (JERICO; SCHEFFER, 2002).

$\mathrm{Na}$ Austrália, Robertson (2003) realizou um estudo por meio de contato telefônico com tutores de 657 cães e estimou que $25,2 \%$ dos animais estavam em sobrepeso, segundo a avaliação do tutor, sendo possível que esta condição tenha sido subestimada, tendo em vista que muitos não reconhecem a condição corporal dos seus animais (TEIXEIRA et al., 2015). No mesmo país, dois anos depois, médicos veterinários foram interrogados sobre a porcentagem de cães com ECC acima de 3 na escala de 5 pontos em atendimentos de clínicas particulares (MCGREEVY et al., 2005). De acordo com as respostas, 2661 cães atendidos por 48 médicos veterinários estavam acima do peso ideal, sendo que 33,5\% apresentavam-se em sobrepeso e 7,6\% eram obesos.

Um ano mais tarde, na França, foi publicado um estudo no qual 681 cães foram avaliados por meio do ECC na escala de 5 pontos e questionário respondido por tutores que levavam seus cães para imunização profilática em um centro de vacinação, no período de fevereiro a março de 2003. Como resultado da avaliação 
destes animais, determinou-se que 33,8\% estavam em sobrepeso e 5,0\% obesos (COLLIARD et al., 2006).

Estudos retrospectivos recentes demonstraram o crescente panorama da obesidade canina dos últimos anos (WEETH et al., 2006; COURCIER et al., 2010; CORBEE, 2013; MAO et al., 2013; USUI; YASUDA; KOKETSU, 2016; ALONSO et al., 2017).

Nos Estados Unidos, foi realizado estudo retrospectivo no qual avaliou-se o ECC na escala de 9 pontos de prontuários de animais saudáveis e pacientes oncológicos, onde foram considerados obesos cães com ECC maior ou igual a 7. Os resultados apontaram que $21,6 \%$ dos cães estavam em sobrepeso e $16,5 \%$ obesos (WEETH et al., 2006). No entanto, pode-se questionar essa prevalência em vista da perda de peso ocasionada em pacientes oncológicos (MICHEL; SORENMO; SHOFER, 2004).

No ano de 2007, no Reino Unido, tutores de 696 cães foram entrevistados por meio de questionário e seus cães foram submetidos à avaliação do ECC na escala de 9 pontos e, estimou-se que 38,9\% dos cães apresentavam-se acima do peso e $20,4 \%$ obesos (COURCIER et al., 2010).

Cães de exposição também foram avaliados por Corbee (2013) na Holanda. Nesse estudo, 1379 animais de 128 diferentes raças foram avaliados. Evidenciou-se que $18,6 \%$ dos cães apresentavam sobrepeso e 1,1\% obesidade. No entanto, os animais avaliados eram cães de exposição que possuem características como a condição corporal adequada para o padrão racial.

Em Beijing, China, foi observado o ECC, na escala de 5 pontos, de 2391 cães atendidos em 14 hospitais veterinários de 7 distritos de forma retrospectiva no período de 2008 a 2011. Como resultado, foi determinado que 44,4\% dos animais apresentavam sobrepeso ou obesidade (MAO et al., 2013).

No Japão, um estudo retrospectivo avaliou dados referentes ao ECC na escala de 5 pontos de 91.200 cães em um período de dez anos (2006 a 2013). Os autores apontaram que 39,8\% dos cães apresentavam-se em sobrepeso e 15,1\% eram obesos (USUI; YASUDA; KOKETSU, 2016).

O estudo mais recente publicado foi realizado nas Ilhas Canárias, na Espanha, onde foram recrutados 93 tutores de cães provenientes do atendimento de dez clínicas veterinárias. O objetivo desse estudo foi avaliar a prevalência da obesidade e a presença de alterações metabólicas associada a esta condição. Os 
autores constataram por meio do ECC na escala de 9 pontos que $40,8 \%$ desta população estava em sobrepeso ou obesa. Além disso, por meio da avaliação de parâmetros sanguíneos e pressão arterial, puderam notar que $22,0 \%$ dos cães avaliados apresentavam alterações compatíveis com disfunção metabólica associada à obesidade, como aumento de triglicerídeos, colesterol e hipertensão (ALONSO et al., 2017).

$\mathrm{Na}$ Tabela 1 está apresentado um compilado de estudos realizados em diferentes países que investigaram a prevalência da obesidade em cães. 
Tabela 1 - Compilado de estudos que investigaram a prevalência de obesidade em cães.

\begin{tabular}{|c|c|c|c|c|c|c|c|c|}
\hline Referência & $\begin{array}{c}\text { Ano de } \\
\text { avaliação }\end{array}$ & $\begin{array}{l}\text { Período } \\
\text { de estudo }\end{array}$ & $\begin{array}{l}\text { Número } \\
\text { de } \\
\text { animais }\end{array}$ & País & Prevalência & $\begin{array}{l}\text { Método de } \\
\text { avaliação }\end{array}$ & $\begin{array}{c}\text { Forma de } \\
\text { investigação }\end{array}$ & Local \\
\hline $\begin{array}{ll}\text { Krook; Larsson; Rooney } \\
\text { (1960) }\end{array}$ & $\begin{array}{c}1930 \mathrm{a} \\
1957\end{array}$ & 27 anos & 10.993 & Suécia & $11,6 \%$ SO & Dados de necrópsia & $\mathrm{R}$ & Setor de patologia \\
\hline Mason (1970) & 1970 & 1 ano & 1.000 & Reino Unido & $28,0 \% \mathrm{SO}$ & Exame físico & $\mathrm{P}$ & Hospital \\
\hline Edney; Smith (1986) & 1983 & 6 meses & 8.268 & Reino Unido & $\begin{array}{l}2,9 \% \mathrm{~S} \\
21,4 \% \mathrm{O}\end{array}$ & Exame físico & $\mathrm{P}$ & Clínicas \\
\hline $\begin{array}{l}\text { Kronfeld; Donoghue; } \\
\text { Glickman (1991) }\end{array}$ & 1986 & 2 anos & 3.729 & Estados Unidos & $\begin{array}{l}22,0 \% \mathrm{~S} \\
0,9 \% \mathrm{O}\end{array}$ & Exame físico & $\mathrm{P}$ & Hospitais \\
\hline Royal Canin (2000) & * & * & 400 & $\begin{array}{c}\text { França, Reino } \\
\text { Unido, Espanha e } \\
\text { Alemanha }\end{array}$ & $\begin{array}{c}2,0 \% \mathrm{O} \\
22,0 \% \mathrm{SO}\end{array}$ & $\begin{array}{c}\text { Informado pelos } \\
\text { tutores }\end{array}$ & $\mathrm{P}$ & Veterinários \\
\hline Jericó ; Scheffer (2002) & * & 1 ano & 648 & Brasil & $16,5 \%$ S0 & Exame físico & $\mathrm{P}$ & $\begin{array}{c}\text { Parques, praças, } \\
\text { hospitais, clínicas e pet } \\
\text { shops }\end{array}$ \\
\hline Robertson (2003) & * & * & 657 & Austrália & $25,0 \% \mathrm{~S}$ & $\begin{array}{l}\text { Informado pelos } \\
\text { tutores }\end{array}$ & $\mathrm{P}$ & Contato telefônico \\
\hline McGreevy et al. (2005) & * & * & 2.661 & Austrália & $\begin{array}{l}33,5 \% \mathrm{~S} \\
7,6 \% \mathrm{O}\end{array}$ & Exame físico & $\mathrm{R}$ & Veterinários \\
\hline Lund et al. (2006) & 1995 & 1 ano & 21.754 & EUA & $\begin{array}{l}29,0 \% \mathrm{~S} \\
5,1 \% \mathrm{O}\end{array}$ & Exame físico & $\mathrm{R}$ & Clínicas \\
\hline Colliard et al. (2006) & 2003 & 1 mês & 616 & França & $\begin{array}{l}38,8 \% \mathrm{~S} \\
5,0 \% \mathrm{O}\end{array}$ & Exame físico & $\mathrm{P}$ & $\begin{array}{l}\text { Vacinação } \\
\text { (ENVA) }\end{array}$ \\
\hline Weeth et al. (2006) & $\begin{array}{c}1999 \text { a } \\
2004\end{array}$ & 5 anos & 14.670 & Estados Unidos & $\begin{array}{l}21,6 \% \text { S } \\
14,8 \% \text { O }\end{array}$ & Exame físico & $\mathrm{R}$ & Hospital \\
\hline
\end{tabular}


Tabela 1 continua...

\begin{tabular}{|c|c|c|c|c|c|c|c|c|}
\hline Courcier et al. (2010) & 2007 & 1 mês & 696 & Reino Unido & $\begin{array}{l}38,9 \% \text { S } \\
20,4 \% \text { O }\end{array}$ & Exame físico & $P$ & $\begin{array}{l}\text { Clínicas e } \\
\text { hospitais }\end{array}$ \\
\hline Corbee (2012) & * & * & 1.379 & Holanda & $\begin{array}{l}18,6 \% \mathrm{~S} \\
1,1 \% \mathrm{O}\end{array}$ & Exame físico & $P$ & Exposição de cães \\
\hline Mao et al. (2013) & $\begin{array}{c}2008 a \\
2011\end{array}$ & 3 anos & 2.391 & China & $44,4 \%$ SO & Exame físico & $\mathrm{R}$ & Hospitais \\
\hline $\begin{array}{l}\text { Usui; Yasuda; Koketsu } \\
\text { (2016) }\end{array}$ & $\begin{array}{c}2006 a \\
2013\end{array}$ & 7 anos & 91.200 & Japão & $\begin{array}{l}39,8 \% \mathrm{~S} \\
15,1 \% \mathrm{O}\end{array}$ & Exame físico & $\mathrm{R}$ & Hospitais \\
\hline Alonso et al. (2017) & * & * & 93 & Espanha & $40,8 \%$ SO & Exame físico & $P$ & $\begin{array}{l}\text { Clínicas e } \\
\text { hospitais }\end{array}$ \\
\hline
\end{tabular}

\%: Prevalência; R: Retrospectivo; P: Prospectivo; S: Sobrepeso; O: Obeso; SO: Sobrepeso e obeso; * informação não apresentada. 


\subsection{Consequências da obesidade}

A obesidade não é apenas o acúmulo de grande quantidade de tecido adiposo, mas também a associação de importantes alterações metabólicas e hormonais que podem culminar na redução da longevidade e na morte (KEALY; LAWLER, 2002; GERMAN, 2006; RAMOS; PITANGA; LESSA, 2010; TVARIJONAVICIUTE et al., 2012; CLARK; HOENIG, 2016).

$\mathrm{Na}$ medicina veterinária, diversas situações nocivas ocorrem em consequência da obesidade tanto pelo excesso de peso mecânico, quanto pela sinalização celular direta, que podem levar a quadros de resistência insulínica, modificação no padrão de adipocinas, hiperlipidemia, acúmulo ectópico de gordura (TOLL et al., 2010; BRUNETTO et al., 2011a; MICHEL, 2004; CHANDLER, 2016; CLARK; HOENIG, 2016), interação do tecido adiposo e sistema imune, além de alteração na produção e secreção de citocinas (LUND et al., 2006; ZORAN, 2010; OSTO; LUTZ, 2015). Um exemplo dessas complicações é em consequência do aumento das adipocinas, como a leptina e adiponectina. Quando em concentrações elevadas, essas substâncias alcançam diferentes tecidos e intensificam as respostas inflamatórias (HUCK et al., 2009; MARSHALL et al., 2009; TOLL et al., 2010; MICHEL, 2012; CHANDLER, 2016; VENDRAMINI, 2019).

As alterações causadas pela obesidade levam a complicações cardiovasculares, locomotoras, hiperlipidemia, afecções orais, pancreatite, alterações respiratórias, afecções orais, dermatites não alérgicas e alguns tipos de neoplasias (GERMAN, 2006; LUND et al., 2006; OSTO; LUTZ, 2015; PEREIRANETO et al., 2018). O animal obeso também possui alterações relacionadas ao controle do apetite, funções imunológicas e neuroendócrinas, além de ser mais vulnerável a complicações em procedimentos anestésicos e cirúrgicos (GERMAN, 2006; LUND et al., 2006; OSTO; LUTZ, 2015; VENDRAMINI, 2019). Dessa forma, é nítido o porquê dos cães obesos apresentarem menor longevidade e qualidade de vida (KEALY; LAWLER, 2002; HUCK et al., 2009; GERMAN et al., 2012). Estes aspectos foram demonstrados no estudo conduzido por Kealy; Lawler (2002), ao avaliarem dois grupos de cães Labradores Retrievers, no qual os animais obesos apresentaram maior incidência de displasia e osteoartrite, além de redução da expectativa de vida. 
Ademais, alterações laboratoriais no perfil lipídico, hiperglicemia e hiperinsulinemia foram observadas em pacientes obesos humanos e caninos. Estudos avaliaram cães obesos e demonstraram que estes animais apresentavam hipercolesterolemia, hipertrigliceridemia (BRUNETTO et al., 2011a; ALONSO et al., 2017), hipertensão e hiperglicemia em jejum (ALONSO et al., 2017). Por meio desses dados, pode-se observar que a obesidade está associada a diversas alterações no metabolismo.

\subsection{Gênese da obesidade}

\subsubsection{Fatores genéticos}

A espécie Canis lúpus familiaris abrange muitas raças com tamanhos diferentes, desde cães toy até raças gigantes (BERMINGHAM et al., 2014). As diferenças raciais não são apenas visuais, mas também em sua anatomia e aptidão (GREER; CANTERBERRY; MURPHY, 2007). Em consequência disto, ocorrem diferenças na composição corporal que predispõem à obesidade em muitas raças (LAUTEN et al., 2001; MCGREEVY et al., 2005; LUND et al., 2006; JEUSETTE et al., 2010; APTEKMANN et al., 2013; OSTO; LUTZ, 2015).

Dentre as raças que estão associadas à maior predisposição ao ganho de peso, destacam-se: Labrador Retriever, Rottweiler, Golden Retriever, Boxer, Basset Hound, Cocker Spaniel, Daschund de pêlo longo e Cavalier King Charles Spaniel (COURCIER et al., 2010b; MAO et al., 2013). Fatores genéticos, como a presença do gene da pró-opiomelanocortina (POMC) que está associado ao aumento do apetite e ao risco de obesidade em cães da raça Labrador Retriever (RAFFAN et al., 2016; DAVISON et al., 2017).

Diferenças na porcentagem de gordura corporal entre as raças já foram estudadas por Jeusette et al. (2010). Nesse estudo, os autores avaliaram, por meio de mensurações morfométricas como ECC e DEXA, 19 cães de seis raças com aptidões diferentes. Os resultados evidenciaram que Greyhounds apresentaram $7,2 \%$ de gordura corporal; Poodles 18,0\%, Dachshunds $15,0 \%$ e Huskies $31,0 \%$, ou seja, cães com o mesmo ECC possuíam diferentes porcentagens de gordura corporal (JEUSETTE et al., 2010). No entanto, esses resultados podem ter sido 
influenciados pelos poucos exemplares de cada raça avaliados, além da prática ou a ausência de atividade física destes animais não ter sido levada em consideração.

Outro aspecto a ser considerado é a necessidade energética de cada animal. Alguns autores sugerem que cães com tamanhos semelhantes, mas de raças diferentes podem apresentar necessidades distintas (BURGER; JOHNSON, 1991). Todavia, essa suposição é controversa, já que em revisão sistemática realizada com base em 29 estudos que descreveram 70 experimentos, os autores concluíram que não foi possível determinar se há distinção entre as raças em vista da grande variabilidade das equações empregadas nos estudos avaliados (BERMINGHAM et al., 2014).

\subsubsection{Gênero e status reprodutivo}

O gênero e status reprodutivo foram previamente associados ao ganho de peso. As fêmeas já foram citadas em vários estudos por apresentarem maior frequência de sobrepeso e obesidade (MCGREEVY et al., 2005; COLLIARD et al., 2006; COURCIER et al., 2010; ZORAN, 2010). Assim como a castração em cadelas, visto que a ovariosalpingohisterectomia leva a lipogênese, alterações no metabolismo energético e alterações hormonais, como redução de estrógeno, hormônio responsável por regular a saciedade (JEUSETTE et al., 2004; ZORAN, 2010). Contudo, essa informação não foi sustentada na meta-análise citada anteriormente, na qual foi observado que a predisposição ao ganho de peso após a castração ocorre independente do sexo (BERMINGHAM et al., 2014).

Por outro lado, a castração também foi citada por reduzir a necessidade energética do animal (ROBERTSON, 2003; COLLIARD et al., 2006; BERMINGHAM et al., 2014; KAWAUCHI et al., 2017). Um estudo que avaliou a alteração do consumo alimentar e da necessidade energética após a esterilização foi realizado por Jeusette et al. (2004). Neste estudo, cadelas da raça Beagle de 2 anos de idade receberam alimento ad libitum e foram avaliadas quanto à necessidade energética $\mathrm{e}$ ao consumo de alimento por seis meses após a cirurgia de ovariosalpingohisterectomia. Os autores notaram que o consumo de alimento aumentou no primeiro mês pós-cirúrgico e se manteve idêntico por mais cinco meses. Este fato ocorreu em conjunto com a redução da necessidade energética 
diária, que trouxe como consequência o ganho de peso das cadelas (JEUSETTE et al., 2004).

Modificações no metabolismo de cães de ambos os sexos e na condição corporal após a castração também foram avaliados por Kawauchi et al. (2017). Os autores observaram que os animais reduziram em 19,4\% a necessidade energética diária após vinte e seis semanas do procedimento cirúrgico. Além de apresentar modificações na quantidade de gordura corporal, sendo encontrado aumento de $21 \%$ de tecido adiposo, embora o peso corporal não tenha sido alterado.

Entretanto, a obesidade não deve ser considerada consequência da castração, uma vez que este procedimento cirúrgico realizado de forma precoce, associado a práticas de exercício e ao controle de energia ingerida foram relatados como recomendações eficazes para a manutenção da condição corporal ideal (SPAIN; SCARLETT; HOUPT, 2004; BROOKS et al., 2014). Em estudo realizado por Salmeri; Olson; Bloomberg (1991), um grupo de cães de ambos os sexos foram castrados antes do primeiro ano de vida e acompanhado por 15 meses. Após este período, não foram observadas diferenças sobre a ingesta e ganho de peso destes animais. Em outro trabalho realizado por Spain; Scarlett; Houpt (2004), os animais foram castrados também jovens e acompanhados por um período maior, 11 anos. Com base nos dados coletados, os autores concluíram que a castração precoce reduziu o risco de obesidade nestes cães (SALMERI; OLSON; BLOOMBERG, 1991; SPAIN; SCARLETT; HOUPT, 2004).

\subsubsection{Idade}

Além do efeito da castração, o avançar da idade pode reduzir a taxa metabólica e o nível de atividade física dos cães (BLAND et al., 2009; COURCIER et al., 2010; ZORAN, 2010). Nos estudos epidemiológicos notou-se maior prevalência de sobrepeso e obesidade em cães de meia idade [de 6 a 10 anos (KRONFELD; DONOGHUE; GLICKMAN, 1991; JERICÓ; SCHEFFER, 2002; LUND et al., 2006; MAO et al., 2013)]. Diferente do estudo realizado por McGreevy et al. (2005), no qual a maior prevalência de cães em sobrepeso e obesos foi observada quando a idade foi superior a 10 anos. Sabe-se que a faixa etária sofre influência direta do porte do cão e nestes estudos, isto não foi levado em consideração (HOSGOOD; SCHOLL, 1998; GREER; CANTERBERRY; MURPHY, 2007). 


\subsubsection{Manejo alimentar}

Assim como fatores relacionados ao animal, o manejo alimentar, no qual estão envolvidos a frequência alimentar e escolha do alimento, influencia de forma direta no desenvolvimento da obesidade. Dessa forma, informações adicionais sobre a dieta como quantidade, ingestão de petiscos e restos de comida devem ser verificados (ROBERTSON, 2003; GERMAN, 2006; LUND et al., 2006; BARTGES et al., 2017). A alimentação ad libitum é considerada a forma mais fácil de manejo alimentar, no entanto, esta prática favorece o consumo excessivo de calorias (KEALY et al., 2002; BROOKS et al., 2014). Tal aspecto foi concluído no estudo conduzido por Kealy et al. (2002), ao avaliaram 48 cães da raça Labrador Retriever. Estes animais foram pareados e divididos em dois grupos, o primeiro recebia alimento ad libitum e o segundo recebia o mesmo alimento, mas em quantidades $25 \%$ menores do que o seu par consumiu no dia anterior. Os cães foram acompanhados por toda vida, no mesmo local, manejo e alimento, diferindo apenas na quantidade diária recebida. Os autores concluíram que o controle alimentar promoveu sobrevida maior de dois anos, além de menor incidência de sobrepeso, obesidade e doenças concomitantes.

A alimentação em quantidade controlada é o método mais indicado para prevenção da obesidade, visto que, desta forma, a quantidade ingerida não excede a necessidade energética (KIENZLE et al., 2002; BROOKS et al., 2014). Para Robertson (2003), os cães devem ser alimentados várias vezes ao dia em pequenas quantidades com intuito de aumentar a perda de energia por termogênese. Já Courcier et al. (2010) discordaram desta informação e afirmaram que a frequência alimentar não está associada ao excesso de peso e sim ao consumo de alimentos em quantidades inespecíficas dos quais são inclusos ração e/ou dieta caseira.

A recomendação de quantidade de alimento apresentada nos rótulos de alguns alimentos pode superestimar a necessidade energética diária dos cães (SÖDER et al., 2016), em virtude da mesma muitas vezes ser baseada na necessidade de cães de laboratório preconizada pelo National Research Council (NRC, 2006). Em estudo realizado por Thes et al. (2016), os autores avaliaram a necessidade energética de manutenção de cães adultos domiciliados de diferentes raças, e observaram que o consumo médio da energia metabolizável dos cães avaliados foi menor que o determinado pelo NRC (2006). Assim como observado por 
Pedrinelli et al. (2018), que sugeriram que as equações preditivas do National Research Council (NRC, 2006), são um ponto de partida para se determinar a necessidade energética de manutenção, no entanto são necessárias avaliações frequentes para evitar o ganho de peso. Ademais, existe a variação individual de cada animal associada à pratica de atividade física, idade, gênero e status reprodutivo (BROOKS et al., 2014; FLANAGAN et al., 2017).

$O$ fornecimento de petiscos pode ser permitido quando em quantidade energética adequada, que não devem exceder $10 \%$ da necessidade energética de manutenção diária (BROOKS et al., 2014). No entanto, a disponibilidade de alimentos palatáveis, com alta concentração de gordura em conjunto com a falta de orientação nutricional pode levar os tutores a fornecerem excesso de energia (BLAND et al., 2009; SENEVIRATNE; SUBASINGHE; WATSON, 2016). Esse fato foi observado por Bland et al. (2009) ao entrevistar tutores de cães, neste estudo, muitos animais obesos recebiam grande quantidade de petiscos e eram alimentados inúmeras vezes.

Em humanos, a rotina corrida faz com que sejam escolhidos alimentos práticos e rápidos, que em sua maioria agregam grande quantidade de energia em sua dieta (VELÁSQUEZ-MELÉNDEZ; PIMENTA; KAC, 2004). Vale salientar que esse consumo é permitido na dieta, porém de forma ocasional, sendo necessário o consumo de frutas e hortaliças de forma regular (VIEIRA et al., 2001; Ministério da Saúde, 2014).

\subsubsection{Interação cão e tutor}

O estreitamento do vínculo entre o homem e os cães, tornou os pets membros das famílias modernas (BARTGES et al., 2017; CHANDLER et al., 2017). Esse laço pode ser explicado não somente pela companhia e afeto oferecidos pelos cães, mas por desempenharem papel importante na qualidade de vida de seus tutores, com benefícios para a saúde física e mental (WOHLFARTH et al., 2013; GONZÁLEZ RAMÍREZ; LANDERO HERNÁNDEZ, 2014). Entretanto, esta proximidade pode levar os tutores ao comportamento antropomórfico, no qual muitas vezes são transferidos hábitos alimentares errôneos e rotina sedentária aos cães, que podem resultar em consequências negativas como a obesidade (MCGREEVY et al., 2005; COURCIER et al., 2010; BARTGES et al., 2017). Além disso, a condição 
corporal do tutor também pode influenciar no ECC de seus cães. Segundo Kienzle (2012) e Alonso (2017), tutores obesos possuem maior predisposição a possuírem cães nesta mesma condição.

Muitos tutores relacionam o alimento como forma de interação e demonstração de afeto. Esse aspecto associado ao comportamento de mendicância dos cães culminam em consumo excessivo de alimento, o que favorece o ganho de peso e como consequência a obesidade (COLLIARD et al., 2006; COURCIER et al., 2010a; MAO et al., 2013; USUI; YASUDA; KOKETSU, 2016). O excesso de peso corporal não resulta apenas em alterações metabólicas, mas também na interação do cão com seu tutor, pois um animal obeso torna-se incapaz de praticar atividades físicas como caminhadas e brincadeiras. Como consequência, há redução do vínculo humano-animal e dos benefícios que a atividade física em conjunto pode trazer para ambos (MCGREEVY et al., 2005).

Muitos tutores não reconhecem a condição corporal de seus cães e subestimam a obesidade, assim como seus riscos para a saúde de seus animais de estimação (KIENZLE; BERGLER; MANDERNACH, 1998; COLLIARD et al., 2006; BLAND et al., 2009; TEIXEIRA et al., 2015). Com isso, muitos veterinários tornam-se relutantes em informar ao tutor que seu cão está obeso, temendo que esta informação possa ofender, irritar e que de alguma forma possam perder o cliente (BARTGES et al., 2017). Além do mais, medidas para o controle de peso do animal consistem em restrições no consumo de alimentos, o que se torna um problema para muitos tutores, pois os mesmos associam o fornecimento de alimento como forma de interação e demonstração de afeto com seus animais e, a restrição alimentar pode ser encarada por muitos como causa de sofrimento aos cães (KIENZLE; BERGLER; MANDERNACH, 1998; ROUDEBUSH; SCHOENHERR; DELANEY, 2008; MICHEL, 2012).

Fatores relacionados aos tutores podem influenciar e trazer consequências diretas na condição corporal dos cães, dentre os quais pode-se incluir a condição socioeconômica, hábitos alimentares, faixa etária e condição corporal (COLLIARD et al., 2006; COURCIER et al., 2010; ALONSO et al., 2017).

Em estudo conduzido por Courcier et al. (2010) foi possível correlacionar fatores socioeconômicos com a condição corporal dos cães e, os autores concluíram que tutores com menor renda mensal possuíam animais obesos. A baixa classe social também já foi associada à obesidade em pacientes humanos. Isso foi 
justificado pelo baixo padrão na escolha de alimentos e ao maior consumo de alimentos com alto valor calórico, além do excesso de açúcar (LEVY-COSTA et al., 2005; FERREIRA; MAGALHÃES, 2011).

A faixa etária dos tutores também já foi citada como um fator de risco para a obesidade, no qual indivíduos mais velhos possuíam cães em condição corporal acima do ideal (MASON, 1970; COURCIER et al., 2010).

\subsubsection{Diagnóstico da obesidade}

A mensuração do ECC é o método mais utilizado na rotina clínica de pequenos animais, possui fácil aplicabilidade e fornece informações semiquantitativas da composição corporal (LAFLAMME, 1997; WITZEL et al., 2014). Nesta avaliação, são inspecionados e palpados os depósitos de gordura dos animais nas regiões subcutânea, abdominal, musculatura superficial e em regiões de proeminências ósseas (GERMAN, 2006; WITZEL et al., 2014). A visualização da silhueta e da cobertura de gordura é de importante valia na determinação do ECC e deve ser realizada sobre as costelas (LAFLAMME, 1997; GERMAN, 2006). A escala numérica do ECC varia entre 1 a 9 , na qual 1 representa animal magro, 2 e 3 abaixo do peso, 4 e 5 escore ideal, 6 e 7 sobrepeso e 8 e 9 animal obeso (LAFLAMME, 1997). O cão também pode ser classificado como em sobrepeso quando a quantidade de gordura corporal excede $20,0 \%$, e obeso, quando excede $30,0 \%$ (LAFLAMME, 1997).

Equações com base nas medidas morfométricas são utilizadas para estimar a porcentagem de gordura corporal dos cães. As avaliações são realizadas em vários sítios corporais baseando-se na relação das proporções do corpo com o total de massa magra (WITZEL et al., 2014). Em humanos, variáveis antropométricas são realizadas para avaliação de sobrepeso e obesidade. O índice de massa corporal (IMC) é um método muito difundido e utilizado, sendo calculado por meio de uma equação com base na altura e peso do indivíduo. Valores de 18,5 a $24,9 \mathrm{~kg} / \mathrm{m}^{2}$ correspondem a um indivíduo normal. A categoria de sobrepeso condiz com valores de 25,0 a $29,9 \mathrm{~kg} / \mathrm{m}^{2}$ e indivíduos obesos apresentam valores $\geq 30 \mathrm{~kg} / \mathrm{m}^{2}$ (REZENDE et al., 2010; ABESO, 2016; Ministério da Saúde, 2017). Embora seja considerado um bom indicador, o IMC não corresponde à distribuição total de gordura corporal, sendo necessárias mensurações complementares (OMS, 2017). 
Outro parâmetro que pode ser relacionado à condição corporal é a avaliação de circunferências corporais. A mensuração da circunferência de cintura e do abdômen, assim como a razão cintura-quadril, pode variar de acordo com a nacionalidade, sendo que valores de circunferência de cintura $\geq 94 \mathrm{~cm}$ para homens e $\geq 80 \mathrm{~cm}$ para mulheres são atribuídos a fatores de risco para pessoas oriundas da América do Sul (REZENDE et al., 2010; GARVEY et al., 2016). As relações cintura/quadril e cintura/estatura são critérios complementares para avaliação da gordura visceral, sendo consideradas auxiliares no diagnóstico de sobrepeso e obesidade e, também são utilizados como indicadores de risco de doenças cardiovasculares e de síndrome metabólica (RAMOS; PITANGA; LESSA, 2010; REZENDE et al., 2010; ABESO, 2016; OMS, 2017).

\section{OBJETIVO}

\subsection{0bjetivo geral}

Estimar a prevalência de cães obesos domiciliados na cidade de São Paulo SP.

\subsection{Objetivos específicos}

- Determinar os fatores inerentes aos animais associados ao desenvolvimento da obesidade canina;

- Determinar os fatores associados ao manejo empregado ao animal no desenvolvimento da obesidade canina;

- Determinar os fatores associados ao tutor do animal no desenvolvimento da obesidade canina;

- Associar o índice de massa corporal dos tutores com o escore de condição corporal dos cães;

- Avaliar a percepção dos tutores em relação ao escore de condição corporal dos cães; 


\section{MATERIAL E MÉTODOS}

Todo o protocolo experimental foi conduzido de acordo com os princípios éticos de experimentação animal e aprovado pela Comissão de Ética no Uso de Animais da Faculdade de Medicina Veterinária e Zootecnia da Universidade de São Paulo [FMVZ/USP (protocolo número 3443010217)], Comissão de Ética em Pesquisa com Seres Humanos da Escola Superior de Agricultura Luiz de Queiroz da Universidade de São Paulo [ESALQ/USP (protocolo número 71711317.2.0000.5395)], e após prévia autorização dos tutores dos cães incluídos na pesquisa, conforme o Termo de Consentimento Livre e Esclarecido disponibilizado.

\subsection{Seleção dos domicílios}

Este foi um estudo transversal definido como amostra de aglomerados, no qual os cães foram definidos como unidade amostral.

O número de cães avaliados foi definido pela formula de prevalência esperada:

$\frac{1,96 \times \text { prevalência esperada } \times(1-\text { prevalềncia esperada })}{e^{2} o^{2}}$

Foi considerada $15 \%$ como a prevalência esperada da obesidade em cães, baseada em categorizações recentes (USUI; YASUDA; KOKETSU, 2016). Considerou-se o nível de significância da amostra em 95\% e o erro foi definido em 5\% (THRUSFIELD, 2007). Assim, 196 cães foram definidos como número amostral. Para atingir esse número de animais foi determinado que 200 domicílios deveriam ser visitados, baseado no censo realizado no município de São Paulo por Canatto et al. (2012) no qual os autores encontraram que 50\% das casas paulistanas possuíam, em média, dois cães.

Foram sorteados 20 dos 18.228 setores censitários urbanos de São Paulo (IBGE, 2010). Esses foram delimitados em um mapa confeccionado por meio do aplicativo Google Earth/Google Maps. Assim, foi determinado o trajeto percorrido 
dentro de cada região para que se fosse visitado pelo menos dez casas em cada setor.

Para a definição da primeira casa a ser visitada foi realizado sorteio aleatório no software Excel, baseado no número de residências contidas na região censitária, segundo avaliação definida pelo IBGE (2010). Para definição do intervalo que deveria ser realizado entre cada abordagem foi empregada a fórmula:

$X=\left(\frac{Y}{10}\right)$

$\mathrm{X}=$ Intervalo entre casas visitadas;

$\mathrm{Y}=$ Número total de casas da região;

$10=$ número mínimo de casas a serem visitadas.

O número da primeira casa e o intervalo de abordagem estão apresentados no Quadro 1.

Quadro 1 - Definição do primeiro domicílio a ser visitado e o intervalo seguido.

\begin{tabular}{|c|c|c|c|}
\hline $\begin{array}{c}\text { Número do setor } \\
\text { censitário }\end{array}$ & Número de domicílios & Intervalo & $\begin{array}{c}\text { Número do primeiro } \\
\text { domicílio }\end{array}$ \\
\hline 1 & 254 & 25 & 21 \\
\hline 2 & 178 & 18 & 11 \\
\hline 3 & 195 & 20 & 7 \\
\hline 4 & 95 & 10 & 7 \\
\hline 5 & 22 & 0 & 1 \\
\hline 6 & 248 & 25 & 19 \\
\hline 7 & 258 & 26 & 22 \\
\hline 8 & 270 & 27 & 22 \\
\hline 9 & 300 & 30 & 24 \\
\hline 10 & 265 & 27 & 12 \\
\hline 11 & 203 & 20 & 5 \\
\hline 12 & 235 & 24 & 6 \\
\hline 13 & 208 & 21 & 16 \\
\hline 14 & 205 & 21 & 13 \\
\hline 15 & 262 & 26 & 9 \\
\hline 16 & 67 & 7 & 7 \\
\hline 17 & 267 & 27 & 12 \\
\hline 18 & 130 & 13 & 11 \\
\hline 19 & 184 & 18 & 2 \\
\hline 20 & 324 & 32 & 21 \\
\hline
\end{tabular}


Nos casos em que o domicílio foi abordado, mas não se obteve sucesso na entrevista ao tutor ou na avaliação do animal, a casa imediatamente ao lado era visitada de maneira contínua, até se obter sucesso na abordagem.

Os motivos de falhas de obtenção dos dados necessários foram categorizados em: morador que não sabia informações sobre o cão; animais agressivos ou com menos de oito meses de idade; casas sem cães; ausência de morador no domicilio; cães ou tutoras gestantes; ou mesmo recusa na participação do estudo.

\subsection{Avaliação dos cães}

Para obtenção da resenha, informações sanitárias, doenças e características do manejo nutricional dos cães, realizou-se anamnese detalhada (apêndice A).

\subsubsection{Condição corporal}

As avaliações do escore de condição corporal (ECC) e escore de massa muscular (EMM) foram realizadas pelo mesmo médico-veterinário com treino prévio, segundo a escala de nove pontos validada por Laflamme (1997), assim descrita:

ECC 1: animal com costelas, vértebras lombares, ossos pélvicos e todas as proeminências ósseas visíveis à distância. Ausência de gordura corporal perceptível. Perda de massa muscular evidente;

ECC 2: animal com costelas, vértebras lombares e ossos pélvicos facilmente visíveis. Ausência de gordura palpável. Algumas proeminências ósseas podem estar visíveis. Perda mínima de massa muscular;

ECC 3: animal com costelas facilmente palpáveis e podem estar visíveis, sem gordura palpável. Ossos pélvicos tornando-se visíveis. Topo das vértebras lombares visível. Cintura e reentrâncias abdominais evidentes;

ECC 4: animal com costelas facilmente palpáveis, com cobertura adiposa mínima;

ECC 5: animal com costelas palpáveis, sem cobertura adiposa excessiva. Vista de cima, a cintura é observada atrás das costelas. Abdome retraído quando visto de lado; 
ECC 6: animal com costelas palpáveis, com leve excesso de cobertura adiposa. Cintura visível quando vista de cima, mas não é acentuada. Reentrância abdominal aparente;

ECC 7: animal com costelas palpáveis com dificuldade; grossa cobertura adiposa. Depósito de gordura evidente sobre a área lombar e a base da cauda. Cintura ausente ou sutilmente visível. A reentrância abdominal pode estar presente;

ECC 8: Impossível palpar as costelas situadas sob cobertura adiposa muito densa ou palpáveis somente com pressão acentuada. Denso depósito de gordura sobre a região lombar e a base da cauda. Cintura inexistente. Ausência de reentrância abdominal, podendo existir distensão abdominal evidente;

ECC 9: Depósitos de gordura maciços sobre tórax, espinha e base da cauda, pescoço e membros. Distensão abdominal evidente.

O escore de massa muscular (EMM) foi avaliado segundo a escala de 0 a 3 pontos (MICHEL et al., 2011).

EMM 0: Perda muscular expressiva/intensa;

EMM 1: Perda muscular moderada;

EMM 2: Perda muscular leve;

EMM 3: Condição muscular ideal.

\subsubsection{Porte do animal e faixa etária}

Os animais foram classificados quanto ao seu porte e faixa etária de acordo com o Quadro 2.

Quadro 2 - Classificação das faixas etárias caninas, segundo o porte corporal. Adaptado de Hosgood; Scholl (1998).

\begin{tabular}{|c|c|c|c|}
\hline Porte & Jovens & Meia idade & Sênior \\
\hline $\begin{array}{c}\text { Pequeno } \\
(0 \mathrm{a} 10 \mathrm{~kg})\end{array}$ & $<7$ anos & 7 a 12 anos & $>12$ anos \\
\hline $\begin{array}{c}\text { Médio } \\
(10 \mathrm{a} 20 \mathrm{~kg})\end{array}$ & $<6$ anos & 6 a 10 anos & $>10$ anos \\
\hline $\begin{array}{c}\text { Grande } \\
(20 \mathrm{a} 45 \mathrm{~kg})\end{array}$ & $<5$ anos & 5 a 9 anos & $>9$ anos \\
\hline $\begin{array}{c}\text { Gigante } \\
(>45 \mathrm{~kg})\end{array}$ & $<3$ anos & 3 a 7 anos & $>7$ anos \\
\hline
\end{tabular}




\subsubsection{Classificação da frequência de atividade física}

A prática de atividade física dos cães foi classificada segundo as informações fornecidas pelos tutores e, de acordo com os quadros 3 e 4 .

Quadro 3 - Classificação da intensidade de atividade física semanal dos cães avaliados no estudo. Adaptado de Degeling; Lindsay; Mccormack (2012).

\begin{tabular}{|l|l|}
\hline Classificação & Tempo \\
\hline Baixa & $\leq 150$ minutos semanais \\
\hline Ideal & $>150$ minutos semanais \\
\hline
\end{tabular}

Quadro 4 - Classificação da intensidade da atividade física diária dos cães. Adaptado de Degeling; Lindsay; Mccormack (2012).

\begin{tabular}{|l|l|}
\hline Classificação & Tempo \\
\hline Baixa & $\leq 30$ minutos por dia \\
\hline Moderada & $\geq 1$ hora por dia \\
\hline Alta & $\geq 2$ horas por dia \\
\hline
\end{tabular}

\subsection{Avaliação corporal dos tutores}

\subsection{1 Índice de massa corporal}

Para a avaliação do índice de massa corporal dos tutores, realizou-se a avaliação da altura por meio de emprego de fita métrica e pesagem em balança digital portátil (Supermedy ${ }^{\circledR}$, Barueri, São Paulo, Brasil), segundo metodologia recomendada pela organização mundial da saúde (WHO, 2017).

O cálculo do IMC foi determinado através da equação:

$$
\mathrm{IMC}=\frac{\text { Peso Corporal }(\mathrm{Kg})}{\text { Estatura }(\mathrm{m})^{2}}
$$

Os resultados encontrados foram interpretados da seguinte forma: indivíduos com valores inferiores a 18,5 foram considerados como abaixo do peso; indivíduos com valores entre 18,6 e 24,9 foram considerados como eutróficos; indivíduos com valores entre 25,0 e 29,9 foram considerados como em sobrepeso e, indivíduos com valores $\geq 30,0$ foram considerados como obesos. 


\subsubsection{Variáveis antropométricas}

As mensurações antropométricas dos tutores foram realizadas com uma fita métrica, nas quais foram avaliadas a circunferência abdominal, o perímetro da cintura e o perímetro de quadril, segundo metodologia recomendada pela Organização Mundial da Saúde (ABESO, 2016; WHO, 2017).

O perímetro da cintura foi medido sob a roupa do indivíduo, na linha de menor circunferência entre o último arco costal e a borda superior da crista ilíaca; o perímetro de quadril foi medido no ponto de maior protuberância posterior do glúteo; e a circunferência abdominal foi mensurada na região acima da cicatriz umbilical, segundo metodologia descrita por Abeso (2016). Com estas medidas foram calculadas as relações cintura/quadril e cintura/estatura, conforme fórmulas matemáticas abaixo:

Relação cintura quadril $=\frac{\text { Perímetro da cintura }(\mathrm{cm})}{\text { Perímetro do quadril }(\mathrm{cm})}$

Relação cintura estatura $=\frac{\text { Cirucunferência da cintura }(\mathrm{cm})}{\text { Estatura }(\mathrm{cm})}$

Valores de relação cintura/quadril foram interpretados segundo o Quadro 5 (BRAY; GRAY, 1988; CROFT et al., 1995; REZENDE et al., 2010; GARVEY et al., 2016).

Quadro 5 - Valores de referência da relação cintura/quadril, baseado em gênero e idade. Adaptado de Lin et al. (2002) e Huang et al. (2002).

\begin{tabular}{|l|l|l|l|l|}
\hline Sexo & Idade & Baixo & Moderado & Alto \\
\hline Masculino & $18-59$ & $<0,90$ & $0,90-0,96$ & $>0,97$ \\
\hline Masculino & $60-69$ & $<0,91$ & $0,91-0,98$ & $>0,99$ \\
\hline Feminino & $18-59$ & $<0,74$ & $0,74-0,81$ & $>0,82$ \\
\hline Feminino & $60-69$ & $<0,76$ & $0,76-0,83$ & $>0,84$ \\
\hline
\end{tabular}

Valores de risco em relação a cintura/estatura foram considerados como $>0,52$. 


\subsection{Questionário}

Para a avaliação da condição socioeconômica, hábitos alimentares e prática de exercício físico dos tutores foi aplicado um questionário (apêndice B).

\subsubsection{Classificação dos hábitos alimentares dos tutores}

A classificação dos hábitos alimentares dos tutores foi realizada segundo o guia alimentar da população brasileira (Ministério da saúde, 2014) (Quadro 6).

Quadro 6 - Classificação dos hábitos alimentares. Adaptado de Ministério da saúde (2014).

\begin{tabular}{|c|c|c|}
\hline \multirow{2}{*}{ Frequência } & \multicolumn{2}{|c|}{ Alimento } \\
\hline & Frituras e guloseimas & Frutas e vegetais \\
\hline Diário & não saudável & saudável \\
\hline 1 a 2 vezes por semana & saudável & não saudável \\
\hline 3 vezes ou mais & não saudável & saudável \\
\hline Esporadicamente & saudável & não saudável \\
\hline Nunca & saudável & não saudável \\
\hline
\end{tabular}

\subsubsection{Classificação da classe social}

A classificação da renda domiciliar dos tutores foi realizada segundo estudo publicado por Neri [2018 (Quadro 7)].

Quadro 7 - Classificação da renda domiciliar. Adaptado de Neri (2018).

\begin{tabular}{|l|l|}
\hline Renda domiciliar & Classificação \\
\hline Até $R \$ 324$ & Classe baixa \\
\hline De $R \$ 648,00$ até $R \$ 1.164$ & Classe baixa \\
\hline De $R \$ 1.165$ a $R \$ 4.076$ & Classe média \\
\hline De $R \$ 4.077$ a $R \$ 9.920$ & Elite \\
\hline Acima de $R \$ 9.920$ & Elite \\
\hline
\end{tabular}

\subsection{Análise estatística}

Para a análise estatística, procedeu-se a estimativa da prevalência da obesidade nos cães na área urbana do município de São Paulo. Foram considerados dois pesos para cada animal amostrado, um equivalente ao peso do animal no setor censitário onde ele foi avaliado e, um equivalente ao peso do setor 
entre todos os setores do município. O peso do animal no setor foi definido pelo número esperado de animais no setor utilizado na amostragem, que correspondia a $50 \%$ (CANATTO et al., 2012) e o peso do setor foi definido pelo número de domicílios do setor (IBGE, 2010).

Foram realizadas análises descritivas com a frequência de respostas expressas em porcentagem. Para avaliação das diferenças nas proporções de animais em ECC ideal, abaixo do peso, sobrepeso e obesos, as variáveis de interesse em relação ao animal (manejo, características do tutor e as respostas obtidas pelo questionário) e a percepção da condição corporal realizado pelo tutor foi utilizado o teste de qui-quadrado com nível de significância de $5 \%$. Estas análises foram realizadas no software SPSS, versão 20.

Com o objetivo de verificar se houve concordância entre a classificação do ECC realizada pelo médico veterinário e a percepção da condição corporal informada pelo tutor, além do teste de associação do qui-quadrado também foi realizado o teste Kappa ponderado linear $(\mathrm{Kp})$ para avaliar o grau de concordância das informações obtidas. Os resultados foram interpretados segundo as referências do grau de concordância descritos por LANDIS; KOCH (1977) que o considera baixo para valores entre 0,00 a 0,20; razoável entre 0,21 a 0,40; moderado entre 0,41 a 0,60; alto entre 0,61 a 0,80 e quase perfeito, entre 0,81 a 1,00.

Foi realizada também a análise das frequências de cães classificados como obesos, sobrepeso, ideal e abaixo do peso, duas-a-duas, com as variáveis de interesse e em seguida, empregou-se a análise múltipla com análise de correspondência. Para esta análise, as variáveis foram agrupadas em quatro grandes grupos que correspondiam às características físicas dos cães (sexo, idade, porte e status reprodutivo), características do manejo empregado nos cães (alimentação, frequência da alimentação, fornecimento de petiscos, quantidade de alimento e prática de exercícios), características de cuidado com os cães (assistidos pelo médico veterinário e imunização profilática) e características dos tutores (percepção em relação ao ECC do animal, IMC e sexo do tutor). Foram investigados perfis relacionados à classificação de ECC do animal para se avaliar dados qualitativos de resposta não binária. Para a interpretação da intensidade das associações observou-se a representação gráfica dos vetores de cada categoria das variáveis com base em dois critérios principais: a distância dos vetores à origem do eixo formado pela dimensão principal (eixo $x$ ) e o sentido e proximidade entre 
vetores das variáveis. Sendo considerado que quanto mais distante o vetor está de sua origem, menos aleatório o seu comportamento. Assim, quanto mais próximos, maior é a associação. Dessa forma, quando os vetores se apresentaram distantes dos eixos e próximos entre si foram considerados associados. Estas análises foram realizadas no ambiente $\mathrm{R}$ com o pacote "ca".

Para avaliar as chances do animal se tornar obeso ou em sobrepeso, foi realizado o teste de regressão logística múltipla, sendo calculado o odds ratio (OR). Para isso, os cães foram divididos em duas categorias: sobrepeso em conjunto com os obesos versus peso ideal, segundo a classificação do ECC. A associação entre elas foi realizada pelo teste de qui-quadrado e a intensidade da associação com o OR, sendo o intervalo de confiança de $95 \%$. Em seguida, foram escolhidas as variáveis com $p<0,20$ para modelagem de regressão logística múltipla e a determinação do modelo final foi considerada com a OR ajustada para $p<0,05$. 


\section{RESULTADOS}

No total, foram abordados 1198 locais. Destes, 221 domicílios foram incluídos com 285 cães. Os demais foram excluídos devido aos motivos apresentados na Tabela 2.

Tabela 2 - Locais abordados no estudo e motivos de exclusão. São Paulo - SP, 2019.

\begin{tabular}{lcc}
\hline Locais abordados & $\mathbf{N}$ & $\%$ \\
\hline Domicílios com cães, mas com tutores ausentes & 18 & 1,5 \\
Domicílios com a presença de cães agressivos & 8 & 0,7 \\
Domicílios com cães menores de 8 meses de idade & 2 & 0,2 \\
Condomínios de prédios sem acesso & 25 & 2,1 \\
Domicílios incluídos & 221 & 18,4 \\
Domicílios sem a presença de cães & 250 & 20,9 \\
Domicílios com moradores ausentes & 619 & 51,7 \\
Escolas & 2 & 0,2 \\
Cadela gestante & 1 & 0,1 \\
Tutora gestante & 2 & 0,2 \\
Domicílio onde houve recusa do morador & 50 & 4,2 \\
\hline Total de locais abordados & $\mathbf{1 1 9 8}$ & $\mathbf{1 0 0 , 0}$ \\
\hline
\end{tabular}

\subsection{Análise de prevalência}

Por meio de avaliação do ECC de cães incluídos no estudo, determinou-se que a prevalência de obesidade no município de São Paulo é de $14,6 \%$. As prevalências das demais classificações da condição corporal estão apresentadas na Tabela 3 e, as características dos animais em sobrepeso e obesos encontram-se na Tabela 4

Tabela 3 - Prevalência da condição corporal dos 285 cães avaliados no estudo. São Paulo - SP, 2019.

\begin{tabular}{lllll}
\multicolumn{1}{c}{ Classificação do ECC1 } & N & $\mathbf{P}^{2}$ & \multicolumn{2}{c}{ IC 95\% } \\
Inferior & Superior \\
\hline Abaixo do peso (ECC 1 a 3) & 23 & 6,0 & 5,8 & 6,2 \\
Ideal (ECC 4 e 5) & 149 & 53,5 & 53,1 & 53,9 \\
Sobrepeso (ECC 6 e 7) & 75 & 25,9 & 25,6 & 26,2 \\
Obeso (ECC 8 e 9) & 38 & 14,6 & 14,2 & 15,0 \\
\hline
\end{tabular}

${ }^{1} E C C=$ escore de condição corporal; $\mathrm{P}^{2}$ prevalência. 
Tabela 4 - Prevalência dos animais em sobrepeso e obesos avaliados no estudo em diversas características. São Paulo - SP, 2019.

\begin{tabular}{|c|c|c|c|c|c|}
\hline \multirow{2}{*}{ Característica } & \multirow{2}{*}{$\begin{array}{l}\text { Classificação do } \\
\text { ECC }^{1}\end{array}$} & \multirow{2}{*}{$\mathbf{N}$} & \multirow{2}{*}{$\mathbf{P}^{2}$} & \multicolumn{2}{|c|}{ IC $95 \%$} \\
\hline & & & & Inferior & Superior \\
\hline & \multicolumn{5}{|c|}{ Faixa etária $^{3}$} \\
\hline \multirow[t]{2}{*}{ Faixa etária jovem } & Sobrepeso & 40 & 22,2 & 21,7 & 22,6 \\
\hline & Obeso & 19 & 12,6 & 12,3 & 13,0 \\
\hline \multirow{2}{*}{ Faixa etária adulta } & Sobrepeso & 21 & 32,7 & 31,8 & 33,6 \\
\hline & Obeso & 11 & 16,9 & 16,1 & 17,4 \\
\hline \multirow{3}{*}{ Faixa etária senil } & Sobrepeso & 14 & 30,2 & 29,2 & 30,9 \\
\hline & Obeso & 8 & 14,5 & 13,8 & 15,4 \\
\hline & \multicolumn{5}{|c|}{ Porte ${ }^{3}$} \\
\hline \multirow{2}{*}{ Porte pequeno } & Sobrepeso & 41 & 25,2 & 24,7 & 25,7 \\
\hline & Obeso & 21 & 14,5 & 14,1 & 15,0 \\
\hline \multirow{2}{*}{ Porte médio } & Sobrepeso & 21 & 26,4 & 25,8 & 27,1 \\
\hline & Obeso & 8 & 12,0 & 11,2 & 12,5 \\
\hline \multirow{2}{*}{ Porte grande } & Sobrepeso & 13 & 26,8 & 25,8 & 27,7 \\
\hline & Obeso & 9 & 21,0 & 20,2 & 21,8 \\
\hline & \multicolumn{5}{|c|}{ Sexo } \\
\hline \multirow[t]{2}{*}{ Fêmeas } & Sobrepeso & 46 & 28,5 & 28,0 & 29,0 \\
\hline & Obeso & 28 & 20,3 & 19,9 & 20,7 \\
\hline \multirow[t]{3}{*}{ Machos } & Sobrepeso & 29 & 23,0 & 22,4 & 23,5 \\
\hline & Obeso & 10 & 8,4 & 8,0 & 8,7 \\
\hline & \multicolumn{5}{|c|}{ Castração } \\
\hline \multirow[t]{2}{*}{ Castrados } & Sobrepeso & 39 & 31,4 & 30,9 & 31,9 \\
\hline & Obeso & 28 & 22,3 & 21,7 & 22,8 \\
\hline \multirow[t]{2}{*}{ Não castrados } & Sobrepeso & 36 & 20,9 & 20,5 & 21,4 \\
\hline & Obeso & 10 & 7,6 & 7,4 & 7,9 \\
\hline
\end{tabular}

\subsection{Estatística descritiva e associação das características dos cães e} dos tutores e manejo empregados aos animais.

De acordo com a anamnese respondida pelos tutores, foram obtidas informações referentes às características do animal (Tabela 5) e, ao manejo sanitário e nutricional (Tabela 6). Também estão apresentadas as associações das variáveis descritas com a condição corporal dos cães, das quais foi possível observar associação entre o ECC dos cães com o sexo $(p=0,003)$ e status reprodutivo $(p<0,001)$, sendo que a maioria dos animais em sobrepeso e obesos são do sexo feminino e, castrados, independente do sexo.

Em relação aos cuidados com os cães, houve associação entre frequência em que os animais eram assistidos por médico veterinário e o ECC dos cães 
$(p=0,026)$, sendo que os tutores de animais obesos em sua maioria buscavam atendimento apenas em casos de doença.

Houve também associação entre a frequência de alimentação $(p=0,033)$ e a condição corporal dos animais, sendo que os obesos eram alimentados mais de três vezes por dia ou a recebiam ad libitum. Além disso, esses animais também consumiam petiscos, fator que também foi associado com a condição corporal dos cães $(p=0,011)$.

Tabela 5 - Distribuição das características dos 285 cães avaliados, segundo a classificação da condição corporal. São Paulo - SP, 2019.

\begin{tabular}{|c|c|c|c|c|c|c|c|c|c|c|c|}
\hline \multirow[t]{2}{*}{ Característica } & \multicolumn{2}{|c|}{$\begin{array}{c}\text { Abaixo do } \\
\text { peso } \\
(\text { ECC } 1 \text { a 3) }\end{array}$} & \multicolumn{2}{|c|}{$\begin{array}{c}\text { Ideal } \\
\text { (ECC } 4 \text { e } 5)\end{array}$} & \multicolumn{2}{|c|}{$\begin{array}{l}\text { Sobrepeso } \\
\text { (ECC } 6 \text { e } 7)\end{array}$} & \multicolumn{2}{|c|}{$\begin{array}{c}\text { Obeso } \\
\text { (ECC } 8 \text { e 9) }\end{array}$} & \multicolumn{2}{|c|}{$\begin{array}{l}\text { Total de } \\
\text { animais }\end{array}$} & \multirow[t]{2}{*}{$\begin{array}{l}\text { Valor } \\
\text { de } p^{1}\end{array}$} \\
\hline & $\mathbf{N}$ & $\%$ & $\mathbf{N}$ & $\%$ & $\mathbf{N}$ & $\%$ & $\mathbf{N}$ & $\%$ & $\mathbf{N}$ & $\%$ & \\
\hline \multicolumn{12}{|c|}{ Faixa etária ${ }^{2}$} \\
\hline Jovem & 12 & 7,1 & 98 & 58,0 & 40 & 23,7 & 19 & 11,2 & 169 & 100,0 & \multirow{4}{*}{0,191} \\
\hline Adulto & 4 & 6,1 & 30 & 45,5 & 21 & 31,8 & 11 & 16,7 & 66 & 100,0 & \\
\hline Senil & 7 & 14,9 & 18 & 38,3 & 14 & 29,8 & 8 & 17,0 & 47 & 100,0 & \\
\hline Sem informação & 0 & 0,0 & 3 & 100,0 & 0 & 0,0 & 0 & 0,0 & 0 & 100,0 & \\
\hline \multicolumn{12}{|c|}{ Sexo } \\
\hline Fêmea & 11 & 7,3 & 65 & 43,3 & 46 & 30,7 & 28 & 18,7 & 150 & 100,0 & \multirow{2}{*}{0,003} \\
\hline Macho & 12 & 8,9 & 84 & 62,2 & 29 & 21,5 & 10 & 7,4 & 135 & 100,0 & \\
\hline \multicolumn{12}{|c|}{ Raça } \\
\hline $\begin{array}{l}\text { Dobermann } \\
\text { Pinscher }\end{array}$ & 1 & 5,6 & 8 & 44,4 & 5 & 27,8 & 4 & 22,2 & 18 & 100,0 & \\
\hline Labrador & 1 & 10,0 & 2 & 20,0 & 4 & 40,0 & 3 & 30,0 & 10 & 100,0 & \\
\hline Lhasa Apso & 2 & 20,0 & 8 & 80,0 & 0 & 0,0 & 0 & 0,0 & 10 & 100,0 & \\
\hline Outras raças & 3 & 5,6 & 28 & 51,9 & 16 & 29,6 & 7 & 13,0 & 54 & 100,0 & \\
\hline Poodle & 3 & 18,8 & 5 & 31,2 & 5 & 31,2 & 3 & 18,8 & 16 & 100,0 & \\
\hline Shih-tzu & 0 & 0,0 & 13 & 81,2 & 3 & 18,8 & 0 & 0,0 & 16 & 100,0 & \\
\hline Sem raça definida & 12 & 8,7 & 74 & 53,6 & 37 & 26,8 & 15 & 10,9 & 139 & 100,0 & \\
\hline Yorkshire Terrier & 1 & 4,3 & 11 & 47,8 & 5 & 21,7 & 6 & 26,1 & 23 & 100,0 & \\
\hline \multicolumn{12}{|c|}{ Porte $^{2}$} \\
\hline Pequeno & 16 & 10,3 & 78 & 50,0 & 41 & 26,3 & 21 & 13,5 & 156 & 100,0 & \multirow{4}{*}{0,637} \\
\hline Médio & 4 & 5,1 & 45 & 57,7 & 21 & 26,9 & 8 & 10,3 & 78 & 100,0 & \\
\hline Grande & 2 & 4,4 & 21 & 46,7 & 13 & 28,9 & 9 & 20,0 & 45 & 100,0 & \\
\hline Sem informação & 1 & 33,3 & 5 & 66,7 & 0 & 0,0 & 0 & 0,0 & 6 & 100,0 & \\
\hline
\end{tabular}


Tabela 5 continua...

\begin{tabular}{|c|c|c|c|c|c|c|c|c|c|c|c|}
\hline \multicolumn{12}{|c|}{ Status reprodutivo } \\
\hline Sim & 8 & 6,4 & 50 & 40,0 & 39 & 31,2 & 28 & 22,4 & 125 & 100,0 & \multirow{2}{*}{$<0,001$} \\
\hline Não & 15 & 9,4 & 99 & 61,9 & 36 & 22,5 & 10 & 6,2 & 160 & 100,0 & \\
\hline \multicolumn{12}{|c|}{ Sexo e status reprodutivo } \\
\hline Fêmea castradas & 7 & 8,9 & 29 & 36,7 & 24 & 30,4 & 19 & 24,1 & 79 & 100,0 & \multirow{2}{*}{0,404} \\
\hline Macho castrados & 1 & 2,2 & 21 & 45,7 & 15 & 32,6 & 9 & 19,6 & 46 & 100,0 & \\
\hline \multicolumn{12}{|c|}{ Idade da castração } \\
\hline Até 1 ano & 4 & 5,3 & 36 & 47,4 & 21 & 27,6 & 15 & 19,5 & 76 & 100,0 & \\
\hline 1 a 3 anos & 1 & 10,0 & 2 & 20,0 & 4 & 40,0 & 3 & 30,0 & 10 & 100,0 & \\
\hline Mais de 3 anos & 2 & 7,7 & 6 & 23,1 & 10 & 38,5 & 8 & 30,8 & 26 & 100,0 & \\
\hline Não castrados & 15 & 9,4 & 99 & 61,9 & 36 & 22,5 & 10 & 6,2 & 160 & 100,0 & 0,359 \\
\hline Sem informação & 1 & 7,7 & 6 & 46,1 & 4 & 30,8 & 2 & 15,4 & 13 & 100,0 & \\
\hline \multicolumn{12}{|c|}{ Doença relatada pelo tutor } \\
\hline Cardiopatia & 1 & 100,0 & 0 & 0,0 & 0 & 0,0 & 0 & 0,0 & 1 & 100,0 & \\
\hline Colapso de & & & & & & & & 100 & & & \\
\hline traquéia & 0 & 0,0 & 0 & 0,0 & 0 & 0,0 & 1 & 0 & 1 & 100,0 & \\
\hline Dermatopatia & 0 & 0,0 & 3 & 60,0 & 1 & 20,0 & 1 & 20 & 5 & 100,0 & \\
\hline Diabetes mellitus & 0 & 0,0 & 2 & 66,7 & 1 & 33,3 & 0 & 0,0 & 3 & 100,0 & - \\
\hline Epilepsia & 0 & 0,0 & 2 & 100,0 & 0 & 0,0 & 0 & 0,0 & 2 & 100,0 & \\
\hline Neoplasia & 0 & 0,0 & 1 & 50,0 & 1 & 50,0 & 0 & 0,0 & 2 & 100,0 & \\
\hline Ortopédica & 0 & 0,0 & 5 & 62,5 & 1 & 12,5 & 2 & 25 & 8 & 100,0 & \\
\hline Sem diagnóstico & 22 & 9,6 & 136 & 59,4 & 71 & 31,0 & 0 & 0,0 & 229 & 100,0 & \\
\hline
\end{tabular}


Tabela 6 - Manejo sanitário e nutricional realizados pelos tutores dos 285 cães avaliados no estudo, distribuídos segundo a classificação da condição corporal. São Paulo - SP, 2019.

\begin{tabular}{|c|c|c|c|c|c|c|c|c|c|c|c|}
\hline \multirow[t]{2}{*}{ Característica } & \multicolumn{2}{|c|}{$\begin{array}{c}\text { Abaixo do } \\
\text { peso } \\
(E C C 1 \text { a 3) }\end{array}$} & \multicolumn{2}{|c|}{$\begin{array}{c}\text { Ideal } \\
(\text { ECC } 4 \text { e } 5)\end{array}$} & \multicolumn{2}{|c|}{$\begin{array}{l}\text { Sobrepeso } \\
\text { (ECC } 6 \text { e } 7)\end{array}$} & \multicolumn{2}{|c|}{$\begin{array}{c}\text { Obeso } \\
\text { (ECC } 8 \text { e 9) }\end{array}$} & \multicolumn{2}{|c|}{$\begin{array}{l}\text { Total de } \\
\text { animais }\end{array}$} & \multirow[t]{2}{*}{$\begin{array}{l}\text { Valor } \\
\text { de } p^{1}\end{array}$} \\
\hline & $\mathbf{N}$ & $\%$ & $\mathbf{N}$ & $\%$ & $\mathbf{N}$ & $\%$ & $\mathbf{N}$ & $\%$ & $\mathbf{N}$ & $\%$ & \\
\hline \multicolumn{12}{|c|}{ Realizou imunização } \\
\hline Sim & 22 & 8,0 & 143 & 52,0 & 73 & 26,5 & 37 & 13,5 & 275 & 100,0 & \multirow{3}{*}{0,863} \\
\hline Não & 1 & 16,7 & 4 & 66,7 & 1 & 16,7 & 0 & 0,0 & 6 & 100,0 & \\
\hline Não informado & 0 & 0,0 & 2 & 50,0 & 1 & 25,0 & 1 & 25,0 & 4 & 100,0 & \\
\hline \multicolumn{12}{|c|}{ Atualização da imunização } \\
\hline Anual & 19 & 7,7 & 130 & 52,6 & 64 & 25,9 & 34 & 13,8 & 247 & 100,0 & \multirow{4}{*}{0,178} \\
\hline Atrasada & 3 & 10,7 & 13 & 46,4 & 9 & 32,14 & 3 & 10,7 & 28 & 100,0 & \\
\hline Nunca & 1 & 16,7 & 4 & 66,7 & 1 & 16,7 & 0 & 0 & 6 & 100,0 & \\
\hline Não informado & 0 & 0 & 2 & 50,0 & 1 & 25,0 & 1 & 25,0 & 4 & 100,0 & \\
\hline \multicolumn{12}{|c|}{ Imunização realizada em campanha } \\
\hline Sim & 14 & 10,2 & 61 & 44,5 & 36 & 26,3 & 26 & 18,9 & 137 & 100,0 & \multirow{3}{*}{0,118} \\
\hline Não & 8 & 5,6 & 85 & 60,2 & 38 & 26,9 & 10 & 7,1 & 141 & 100,0 & \\
\hline Não informado & 1 & 14,3 & 3 & 42,9 & 1 & 14,3 & 2 & 83,3 & 7 & 100,0 & \\
\hline \multicolumn{12}{|c|}{ Imunização realizada por médico veterinário } \\
\hline Sim & 15 & 6,9 & 114 & 52,3 & 55 & 25,2 & 34 & 15,6 & 218 & 100,0 & \multirow{2}{*}{0,155} \\
\hline Não & 8 & 11,9 & 35 & 52,2 & 20 & 29,9 & 4 & 6,0 & 67 & 100,0 & \\
\hline
\end{tabular}

Foram assistidos em algum momento por um médico veterinário

\begin{tabular}{|c|c|c|c|c|c|c|c|c|c|c|c|}
\hline Sim & 17 & 7,0 & 125 & 51,2 & 65 & 26,6 & 37 & 15,2 & 244 & 100,0 & \multirow{2}{*}{0,091} \\
\hline Não & 6 & 15,8 & 23 & 60,5 & 10 & 23,7 & 0 & 0,0 & 39 & 100,0 & \\
\hline \multicolumn{12}{|c|}{ Frequência em que eram assistidos por um médico veterinário } \\
\hline Frequente & 2 & 2,3 & 54 & 61,4 & 19 & 21,6 & 13 & 14,8 & 88 & 100,0 & \multirow{4}{*}{0,026} \\
\hline Nunca & 4 & 12,9 & 19 & 61,3 & 8 & 25,8 & 0 & 0,0 & 31 & 100,0 & \\
\hline Só doente & 16 & 10,1 & 73 & 45,9 & 46 & 28,9 & 24 & 15,1 & 159 & 100,0 & \\
\hline Não informado & 1 & 14,3 & 3 & 42,9 & 2 & 28,6 & 1 & 14,3 & 7 & 100,0 & \\
\hline \multicolumn{12}{|c|}{ Tipo de alimento fornecido } \\
\hline Comida & 1 & 8,3 & 7 & 58,3 & 2 & 16,7 & 2 & 16,7 & 12 & 100,0 & \multirow{4}{*}{0,864} \\
\hline Ração & 17 & 8,4 & 104 & 51,5 & 54 & 26,7 & 27 & 13,4 & 202 & 100,0 & \\
\hline $\begin{array}{l}\text { Ração + comida } \\
\text { e/ou resto }\end{array}$ & 5 & 7,2 & 38 & 55,1 & 18 & 26,1 & 8 & 11,6 & 69 & 100,0 & \\
\hline Não informado & 0 & 0,0 & 0 & 0,0 & 1 & 50,0 & 1 & 50,0 & 2 & 100,0 & \\
\hline
\end{tabular}


Tabela 6 continua...

\begin{tabular}{|c|c|c|c|c|c|c|c|c|c|c|c|}
\hline \multicolumn{12}{|c|}{ Frequência de alimentar } \\
\hline 1 vez ao dia & 0 & 0,0 & 10 & 58,8 & 6 & 35,3 & 1 & 5,9 & 17 & 100,0 & \\
\hline 2 vezes ao dia & 3 & 2,6 & 62 & 53,9 & 34 & 29,6 & 16 & 13,9 & 115 & 100,0 & \\
\hline $\begin{array}{l}3 \text { ou mais vezes } \\
\text { ao dia }\end{array}$ & 5 & 10,2 & 31 & 63,3 & 9 & 18,4 & 4 & 8,2 & 49 & 100,0 & 0,033 \\
\hline Livre & 15 & 14,7 & 46 & 45,1 & 25 & 24,5 & 16 & 15,7 & 102 & 100,0 & \\
\hline Não informado & 0 & 0,0 & 0 & 0,0 & 1 & 50,0 & 1 & 50,0 & 2 & 100,0 & \\
\hline \multicolumn{12}{|c|}{ Quantificação do alimento fornecido } \\
\hline Inespecífica & 23 & 9,7 & 121 & 51,1 & 64 & 32,6 & 31 & 12,7 & 239 & 100,0 & 195 \\
\hline Pesada & 0 & 0,0 & 28 & 60,9 & 11 & 23,9 & 7 & 15,2 & 46 & 100,0 & 0 \\
\hline \multicolumn{12}{|c|}{ Critério para determinar a quantidade de alimento } \\
\hline $\begin{array}{l}\text { Balconista ou } \\
\text { criador }\end{array}$ & 0 & 0,0 & 1 & 50,0 & 1 & 50,0 & 0 & 0,0 & 2 & 100,0 & \\
\hline Rótulo & 0 & 0,0 & 17 & 73,9 & 3 & 13,0 & 3 & 13,0 & 23 & 100,0 & \\
\hline $\begin{array}{l}\text { Médico } \\
\text { veterinário }\end{array}$ & 0 & 0,0 & 22 & 55,3 & 11 & 28,9 & 6 & 15,8 & 39 & 100,0 & 0,503 \\
\hline $\begin{array}{l}\text { Não foi } \\
\text { determinada }\end{array}$ & 23 & 13,7 & 109 & 65,5 & 60 & 35,7 & 29 & 17,3 & 221 & 100,0 & \\
\hline \multicolumn{12}{|c|}{ Classificação por energia metabolizável (kcal) do alimento fornecido } \\
\hline Até 3550 kcal & 10 & 9,3 & 49 & 45,8 & 30 & 28,0 & 18 & 16,8 & 107 & 100,0 & \\
\hline $\begin{array}{l}3551 \text { a } 3800 \\
\text { kcal }\end{array}$ & 3 & 5,2 & 34 & 58,6 & 15 & 25,9 & 6 & 10,3 & 58 & 100,0 & 0,345 \\
\hline $\begin{array}{l}\text { Acima de } 3801 \\
\text { kcal }\end{array}$ & 1 & 2,3 & 28 & 63,6 & 9 & 20,5 & 6 & 13,6 & 44 & 100,0 & \\
\hline Sem informação & 9 & 11,8 & 38 & 50,0 & 21 & 27,7 & 8 & 10,5 & 76 & 100,0 & \\
\hline \multicolumn{12}{|c|}{ Fornecimento de petisco } \\
\hline Sim & 10 & 5,1 & 102 & 52,0 & 52 & 26,5 & 32 & 16,3 & 196 & 100,0 & 0011 \\
\hline Não & 13 & 14,6 & 47 & 52,8 & 23 & 25,8 & 6 & 6,7 & 89 & 100,0 & ו \\
\hline \multicolumn{12}{|c|}{ Classificação do petisco fornecido } \\
\hline Humanos & 3 & 3,9 & 38 & 50,0 & 17 & 22,4 & 18 & 23,7 & 76 & 100,0 & \\
\hline Caninos & 1 & 2,6 & 22 & 57,9 & 9 & 23,7 & 6 & 15,8 & 38 & 100,0 & Q 271 \\
\hline $\begin{array}{l}\text { Humanos e } \\
\text { caninos }\end{array}$ & 6 & 7,3 & 42 & 51,2 & 26 & 31,7 & 8 & 9,7 & 82 & 100,0 & 1 \\
\hline
\end{tabular}


Tabela 6 continua...

\begin{tabular}{|c|c|c|c|c|c|c|c|c|c|c|c|}
\hline \multicolumn{12}{|c|}{ Pratica de atividade física diária } \\
\hline Baixa & 3 & 9,4 & 21 & 65,6 & 7 & 21,9 & 1 & 3,1 & 32 & 100,0 & \multirow{3}{*}{0,265} \\
\hline Moderada & 0 & 0,0 & 15 & 65,6 & 5 & 21,7 & 3 & 13,0 & 23 & 100,0 & \\
\hline $\begin{array}{l}\text { Não pratica } \\
\text { diariamente }\end{array}$ & 20 & 8,7 & 113 & 48,1 & 63 & 27,4 & 34 & 14,8 & 230 & 100,0 & \\
\hline \multicolumn{12}{|c|}{ Prática de atividade física semanal } \\
\hline$\leq 150$ horas & 5 & 5,4 & 54 & 58,1 & 21 & 22,6 & 13 & 14,0 & 93 & 100,0 & \multirow{3}{*}{0,856} \\
\hline$>150$ horas & 3 & 7,1 & 24 & 57,1 & 11 & 26,2 & 4 & 9,5 & 42 & 100,0 & \\
\hline $\begin{array}{l}\text { Não pratica } \\
\text { atividade }\end{array}$ & 15 & 10,0 & 71 & 47,3 & 43 & 28,6 & 21 & 14,0 & 150 & 100,0 & \\
\hline \multicolumn{12}{|c|}{ Presença de contactante no domicílio } \\
\hline Caninos & 8 & 6,5 & 54 & 43,9 & 40 & 32,5 & 21 & 17,1 & 93 & 100,0 & \multirow{4}{*}{0,289} \\
\hline Felinos & 0 & 0,0 & 5 & 71,4 & 2 & 28,6 & 0 & 0,0 & 7 & 100,0 & \\
\hline $\begin{array}{l}\text { Caninos e } \\
\text { felinos }\end{array}$ & 0 & 0,0 & 6 & 85,7 & 1 & 14,3 & 0 & 0,0 & 7 & 100,0 & \\
\hline Sem contactante & 15 & 10,1 & 84 & 56,7 & 32 & 21,6 & 17 & 11,5 & 148 & 100,0 & \\
\hline \multicolumn{12}{|c|}{ Local de moradia } \\
\hline Casa & 19 & 9,1 & 107 & 51,2 & 57 & 27,3 & 26 & 12,5 & 209 & 100,0 & \multirow{2}{*}{0,587} \\
\hline Apartamento & 4 & 5,2 & 42 & 55,2 & 18 & 23,7 & 12 & 15,8 & 76 & 100,0 & \\
\hline
\end{tabular}

Legenda: ECC: escore de condição corporal; ${ }^{1}$ Valor de $p$ referente ao teste de qui- quadrado;

Foram incluídos 221 tutores de 285 cães e, destes, 168 possuíam apenas um cão, 44 deles possuíam dois cães, sete eram tutores de três cães e dois possuíam quatro cães. Devido ao fato dos tutores possuírem animais em diferentes classificações de ECC, optou-se por avaliar cada animal separadamente, ou seja, existem informações dos tutores em duplicata, visto que as variáveis foram associadas à condição corporal de cada animal.

Informações sobre as características socioeconômicas dos tutores estão apresentadas na Tabela 7; o perfil nutricional e atividade física na Tabela 8; classificação do IMC e as mensurações morfométricas na Tabela 9. Foi possível observar que a maioria dos tutores de cães em sobrepeso e obesos possuíam hábitos alimentares não saudáveis, referente ao consumo de guloseimas e, isso apresentou associação com a condição corporal dos cães $(p=0,005)$. 
Tabela 7 - Distribuição das características socioeconômicas dos tutores entrevistados, distribuídos segundo a classificação da condição corporal dos cães. São Paulo - SP, 2019.

\begin{tabular}{|c|c|c|c|c|c|c|c|c|c|c|c|}
\hline \multirow[t]{2}{*}{ Característica } & \multicolumn{2}{|c|}{$\begin{array}{l}\text { Abaixo do } \\
\text { peso } \\
(\text { ECC 1 a 3) }\end{array}$} & \multicolumn{2}{|c|}{$\begin{array}{c}\text { Ideal } \\
\text { (ECC } 4 \text { e } 5)\end{array}$} & \multicolumn{2}{|c|}{$\begin{array}{l}\text { Sobrepeso } \\
\text { (ECC } 6 \text { e } 7)\end{array}$} & \multicolumn{2}{|c|}{$\begin{array}{l}\text { Obeso } \\
\text { (ECC } 8 \text { e } 9)\end{array}$} & \multicolumn{2}{|c|}{$\begin{array}{l}\text { Total de } \\
\text { animais }\end{array}$} & \multirow[t]{2}{*}{$\begin{array}{c}\text { Valor de } \\
\qquad \mathbf{p}^{1}\end{array}$} \\
\hline & $\mathbf{N}$ & $\%$ & $\mathbf{N}$ & $\%$ & $\mathbf{N}$ & $\%$ & $\mathbf{N}$ & $\%$ & $\mathbf{N}$ & $\%$ & \\
\hline \multicolumn{12}{|c|}{ Gênero } \\
\hline Masculino & 8 & 7,8 & 57 & 55,3 & 25 & 24,3 & 13 & 12,6 & 103 & 100,0 & \multirow{2}{*}{0,800} \\
\hline Feminino & 115 & 40,5 & 94 & 33,1 & 50 & 17,6 & 25 & 8,8 & 284 & 100,0 & \\
\hline \multicolumn{12}{|c|}{ Faixa etária } \\
\hline $\begin{array}{l}\text { Entre } 18 \text { e } 34 \\
\text { anos }\end{array}$ & 9 & 10,2 & 50 & 56,8 & 14 & 15,9 & 15 & 17,0 & 88 & 100,0 & \\
\hline $\begin{array}{l}\text { Entre } 35 \text { e } 59 \\
\text { anos }\end{array}$ & 12 & 9,0 & 68 & 50,7 & 42 & 31,3 & 12 & 9,0 & 134 & 100,0 & 0,094 \\
\hline Acima de 60 anos & 2 & 3,3 & 28 & 46,7 & 19 & 31,7 & 11 & 18,3 & 60 & 100,0 & \\
\hline \multicolumn{12}{|c|}{ Escolaridade } \\
\hline Não estudou & 1 & 50,0 & 1 & 50,0 & 0 & 0,0 & 0 & 0,0 & 2 & 100,0 & \multirow{5}{*}{0,240} \\
\hline $\begin{array}{l}\text { Ensino } \\
\text { fundamental }\end{array}$ & 8 & 14,3 & 23 & 41,1 & 17 & 30,3 & 8 & 14,3 & 56 & 100,0 & \\
\hline Ensino médio & 9 & 7,4 & 65 & 53,2 & 32 & 26,2 & 16 & 13,1 & 122 & 100,0 & \\
\hline Ensino superior & 4 & 3,9 & 59 & 57,8 & 25 & 24,5 & 14 & 13,7 & 102 & 100,0 & \\
\hline Não informou & 1 & 33,3 & 1 & 33,3 & 1 & 33,33 & 0 & 0,0 & 3 & 100,0 & \\
\hline \multicolumn{12}{|c|}{ Renda familiar } \\
\hline Classe baixa & 7 & 12,5 & 25 & 44,6 & 18 & 32,1 & 6 & 10,7 & 56 & 100,0 & \multirow{4}{*}{0,533} \\
\hline Classe média & 8 & 6,6 & 66 & 54,5 & 28 & 23,1 & 19 & 15,7 & 121 & 100,0 & \\
\hline Classe alta & 6 & 5,9 & 58 & 56,8 & 26 & 25,4 & 12 & 11,7 & 102 & 100,0 & \\
\hline Não informou & 2 & 33,3 & 0 & 0,0 & 3 & 50,0 & 1 & 16,7 & 6 & 100,0 & \\
\hline
\end{tabular}

Legenda: ECC: escore de condição corporal; ${ }^{1}$ Valor de $p$ referente ao teste de qui- quadrado. 
Tabela 8 - Distribuição das características do perfil nutricional e atividade física dos tutores entrevistados, segundo a classificação da condição corporal dos cães. São Paulo - SP, 2019.

\begin{tabular}{|c|c|c|c|c|c|c|c|c|c|c|c|}
\hline \multirow[t]{2}{*}{ Característica } & \multicolumn{2}{|c|}{$\begin{array}{c}\text { Abaixo do } \\
\text { peso } \\
\text { (ECC 1 a 3) }\end{array}$} & \multicolumn{2}{|c|}{$\begin{array}{c}\text { Ideal } \\
\text { (ECC } 4 \text { e 5) }\end{array}$} & \multicolumn{2}{|c|}{$\begin{array}{l}\text { Sobrepeso } \\
\text { (ECC } 6 \text { e } 7)\end{array}$} & \multicolumn{3}{|c|}{$\begin{array}{c}\text { Obeso } \\
\text { (ECC } 8 \text { e } 9)\end{array}$} & $\begin{array}{l}\text { Total de } \\
\text { animais }\end{array}$ & \multirow[t]{2}{*}{ Valor de $\mathbf{p}^{1}$} \\
\hline & $\mathbf{N}$ & $\%$ & $\mathbf{N}$ & $\%$ & $\mathbf{N}$ & $\%$ & $\mathbf{N}$ & $\%$ & $\mathbf{N}$ & $\%$ & \\
\hline \multicolumn{12}{|c|}{ Prática de atividade física } \\
\hline Sim & 8 & 7,1 & 68 & 60,2 & 31 & 27,4 & 6 & 5,3 & 113 & 100,0 & \multirow{2}{*}{0,406} \\
\hline Não & 15 & 9,6 & 81 & 51,6 & 44 & 28,0 & 17 & 10,8 & 157 & 100,0 & \\
\hline \multicolumn{12}{|c|}{ Consumo de frituras } \\
\hline Saudável & 11 & 7,6 & 79 & 54,5 & 40 & 27,6 & 15 & 10,3 & 145 & 100,0 & \multirow{2}{*}{0,339} \\
\hline Não saudável & 12 & 8,6 & 70 & 50,0 & 35 & 25,0 & 23 & 16,4 & 140 & 100,0 & \\
\hline \multicolumn{12}{|c|}{ Consumo de frutas } \\
\hline Saudável & 15 & 7,7 & 97 & 49,5 & 57 & 29,1 & 27 & 13,8 & 196 & 100,0 & \multirow{2}{*}{0,200} \\
\hline Não saudável & 8 & 9,0 & 52 & 58,4 & 18 & 20,2 & 11 & 12,4 & 89 & 100,0 & \\
\hline \multicolumn{12}{|c|}{ Consumo de vegetais } \\
\hline Saudável & 10 & 7,0 & 86 & 60,1 & 27 & 18,9 & 20 & 14,0 & 143 & 100,0 & \multirow{2}{*}{0,659} \\
\hline Não saudável & 13 & 9,2 & 63 & 44,4 & 48 & 33,8 & 18 & 12,7 & 142 & 100,0 & \\
\hline \multicolumn{12}{|c|}{ Consumo de guloseimas } \\
\hline Saudável & 7 & 5,6 & 81 & 64,8 & 27 & 21,6 & 10 & 8,0 & 125 & 100,0 & \multirow{2}{*}{0,005} \\
\hline Não saudável & 16 & 10,0 & 68 & 42,5 & 48 & 30,0 & 28 & 17,5 & 160 & 100,0 & \\
\hline
\end{tabular}

Legenda: ECC: escore de condição corporal; ${ }^{1}$ Valor de $p$ referente ao teste de qui- quadrado. 
Tabela 9 - Distribuição das características dos tutores entrevistados, segundo a classificação da condição corporal dos cães. São Paulo - SP, 2019.

\begin{tabular}{|c|c|c|c|c|c|c|c|c|c|c|c|}
\hline \multirow[t]{2}{*}{ Característica } & \multicolumn{2}{|c|}{$\begin{array}{l}\text { Abaixo do } \\
\text { peso } \\
\text { (ECC } 1 \text { a 3) }\end{array}$} & \multicolumn{2}{|c|}{$\begin{array}{c}\text { Ideal } \\
\text { (ECC } 4 \text { e } 5)\end{array}$} & \multicolumn{2}{|c|}{$\begin{array}{l}\text { Sobrepeso } \\
\text { (ECC 6 e 7) }\end{array}$} & \multicolumn{2}{|c|}{$\begin{array}{c}\text { Obeso } \\
\text { (ECC } 8 \text { e 9) }\end{array}$} & \multicolumn{2}{|c|}{$\begin{array}{l}\text { Total de } \\
\text { animais }\end{array}$} & \multirow[t]{2}{*}{ Valor de $p$} \\
\hline & $\mathbf{N}$ & $\%$ & $\mathbf{N}$ & $\%$ & $\mathbf{N}$ & $\%$ & $\mathbf{N}$ & $\%$ & $\mathbf{N}$ & $\%$ & \\
\hline \multicolumn{11}{|c|}{ Classificação do índice de massa corporal } & \multirow{6}{*}{0,384} \\
\hline Abaixo do peso & 1 & 20,0 & 2 & 40,0 & 1 & 20,0 & 1 & 20,0 & 5 & 100,0 & \\
\hline Normal & 9 & 7,7 & 60 & 51,3 & 34 & 29,1 & 14 & 12,0 & 117 & 100,0 & \\
\hline Sobrepeso & 8 & 10,0 & 36 & 45,0 & 22 & 27,5 & 14 & 17,5 & 80 & 100,0 & \\
\hline Obesidade & 3 & 3,9 & 50 & 64,9 & 15 & 19,5 & 9 & 11,7 & 77 & 100,0 & \\
\hline Não informado & 2 & 33,3 & 1 & 16,7 & 3 & 50,0 & 0 & 0,0 & 6 & 100,0 & \\
\hline \multicolumn{12}{|c|}{ Relação cintura/quadril } \\
\hline Sem risco & 6 & 7,1 & 47 & 55,3 & 23 & 27,1 & 9 & 10,6 & 85 & 100,0 & \\
\hline $\begin{array}{l}\text { Em risco } \\
\text { moderado }\end{array}$ & 9 & 11,5 & 45 & 57,7 & 16 & 20,5 & 8 & 10,3 & 78 & 100,0 & \\
\hline $\begin{array}{l}\text { Em risco alto e } \\
\text { muito alto }\end{array}$ & 6 & 5,2 & 55 & 47,8 & 33 & 28,7 & 21 & 18,3 & 115 & 100,0 & 0,254 \\
\hline Não informado & 2 & 28,6 & 2 & 28,6 & 3 & 42,8 & 0 & 0,0 & 7 & 100,0 & \\
\hline \multicolumn{12}{|c|}{ Relação estatura cintura } \\
\hline Sem risco & 12 & 8,7 & 70 & 50,7 & 39 & 28,3 & 17 & 12,3 & 138 & 100,0 & \\
\hline Em risco & 9 & 6,4 & 78 & 55,3 & 33 & 23,4 & 21 & 14,9 & 141 & 100,0 & 0,626 \\
\hline Não informado & 2 & 33,3 & 1 & 16,7 & 3 & 50,0 & 0 & 0,0 & 6 & 100,0 & \\
\hline \multicolumn{12}{|c|}{ Classificação da circunferência abdominal } \\
\hline Sem risco & 10 & 8,1 & 68 & 54,8 & 32 & 25,8 & 14 & 11,3 & 124 & 100,0 & \\
\hline Em risco & 12 & 7,6 & 80 & 50,6 & 42 & 26,6 & 24 & 15,2 & 158 & 100,0 & 0,788 \\
\hline Não informado & 1 & 33,3 & 1 & 33,3 & 1 & 33,3 & 0 & 0,0 & 3 & 100,0 & \\
\hline
\end{tabular}

Legenda: ECC: escore de condição corporal; ${ }^{1}$ Valor de $p$ referente ao teste de qui- quadrado.

$\mathrm{Na}$ Tabela 10 estão apresentadas as informações sobre os moradores dos domicílios, nas quais foi possível notar associação entre a presença de idoso e a condição corporal dos animais $(p=0,006)$, sendo que na maioria das residências dos cães obesos pessoas com idade avançada estavam presentes. 
Tabela 10 - Distribuição das informações sobre os moradores dos domicílios avaliados, segundo a classificação da condição corporal dos cães. São Paulo - SP, 2019.

\begin{tabular}{|c|c|c|c|c|c|c|c|c|c|c|c|}
\hline \multirow{2}{*}{ Característica } & \multicolumn{2}{|c|}{$\begin{array}{l}\text { Abaixo do } \\
\text { peso } \\
(\text { ECC 1 a 3) }\end{array}$} & \multicolumn{2}{|c|}{$\begin{array}{c}\text { Ideal } \\
\text { (ECC } 4 \text { e 5) }\end{array}$} & \multicolumn{2}{|c|}{$\begin{array}{l}\text { Sobrepeso } \\
\text { (ECC } 6 \text { e } 7)\end{array}$} & \multicolumn{2}{|c|}{$\begin{array}{c}\text { Obeso } \\
\text { (ECC } 8 \text { e 9) }\end{array}$} & \multicolumn{2}{|c|}{$\begin{array}{l}\text { Total de } \\
\text { animais }\end{array}$} & \multirow{2}{*}{$\begin{array}{c}\text { Valor de } \\
\qquad \mathbf{p}^{1}\end{array}$} \\
\hline & $\mathbf{N}$ & $\%$ & $\mathbf{N}$ & $\%$ & $\mathbf{N}$ & $\%$ & $\mathbf{N}$ & $\%$ & $\mathbf{N}$ & $\%$ & \\
\hline \multicolumn{12}{|c|}{ Ocupação do tutor } \\
\hline Fora de casa & 9 & 6,5 & 80 & 53,6 & 39 & 28,3 & 16 & 11,6 & 138 & 100,0 & \multirow{2}{*}{0,465} \\
\hline Em casa & 14 & 10,2 & 69 & 47,4 & 36 & 26,3 & 22 & 16,1 & 137 & 100,0 & \\
\hline \multicolumn{12}{|c|}{ Presença de crianças no domicilio } \\
\hline Sim & 9 & 10,1 & 49 & 55,1 & 22 & 24,7 & 9 & 10,1 & 89 & 100,0 & 0,749 \\
\hline Não & 14 & 7,1 & 100 & 51,0 & 53 & 27,0 & 29 & 14,8 & 196 & 100,0 & \\
\hline \multicolumn{12}{|c|}{ Presença de idosos no domicilio } \\
\hline Sim & 10 & 5,7 & 106 & 60,9 & 34 & 19,5 & 24 & 13,8 & 174 & 100,0 & 0,006 \\
\hline Não & 13 & 11,7 & 43 & 38,7 & 41 & 36,9 & 14 & 12,6 & 111 & 100,0 & \\
\hline
\end{tabular}

Legenda: ECC: escore de condição corporal; ${ }^{1}$ Valor de $p$ referente ao teste de qui- quadrado.

\subsection{Percepção do tutor frente ao escore de condição corporal do animal}

A percepção dos tutores sobre a condição corporal dos seus cães não foi condizente com a avaliação da real condição [ $p<0,001$ (Tabela 11)], ou seja, a maioria dos tutores de cães obesos $(52,6 \%)$ os classificaram apenas em sobrepeso. Por outro lado, a maioria dos tutores de cães em sobrepeso $(62,7 \%)$ os consideraram em condição ideal.

Foi realizado o teste de Kappa para averiguar a concordância das informações, que a classificou como razoável $(\mathrm{KP}=0,285)$.

Tabela 11- Classificação do escore de condição corporal atribuído pelo tutor do animal com base no questionário respondido. São Paulo - SP, 2019.

\begin{tabular}{lcccccccc}
\hline \multirow{2}{*}{ Percepção do tutor } & \multicolumn{9}{c}{ Classificação do animal } \\
\cline { 2 - 10 } & $\begin{array}{c}\text { Abaixo do peso } \\
\text { (ECC 1 a 3) }\end{array}$ & \multicolumn{2}{c}{$\begin{array}{c}\text { Ideal } \\
\text { (ECC 4 e 5) }\end{array}$} & $\begin{array}{c}\text { Sobrepeso } \\
\text { (ECC 6 e 7) }\end{array}$ & $\begin{array}{c}\text { Obeso } \\
\text { (ECC 8 e 9) }\end{array}$ \\
\hline Abaixo & $\mathbf{N}$ & $\%$ & $\mathbf{N}$ & $\%$ & $\mathbf{N}$ & $\%$ & $\mathbf{N}$ & $\%$ \\
Ideal & 6 & 26,1 & 11 & 7,4 & 0 & 0,0 & 0 & 0,0 \\
Sobrepeso & 16 & 69,6 & 127 & 85,2 & 47 & 62,7 & 10 & 26,3 \\
Obeso & 1 & 4,3 & 10 & 6,7 & 28 & 37,3 & 20 & 52,6 \\
Total & 0 & 0,0 & 1 & 0,7 & 0 & 0,0 & 8 & 21,1 \\
\hline
\end{tabular}

Legenda: ECC: escore de condição corporal. 


\subsection{Análise de correspondência múltipla}

Com o objetivo de avaliar possíveis relações entre as categorias dos animais e as variáveis incluídas, realizou-se o teste de correspondência múltipla, o qual foi interpretado segundo a intensidade das associações e a representação gráfica dos vetores de cada categoria das variáveis. Foram considerados associados os vetores mais distantes dos eixos e mais próximos entre si.

Dessa forma, conforme ilustrado nas Figuras 1 e 2, foi possível observar que; perfil A: cães castrados que são assistidos com frequência pelo médico veterinário estão mais associados à obesidade; perfil B: machos não castrados que recebem alimentação ad libitum apresentaram maior associação com a condição corporal ideal ou abaixo do peso; perfil C: domicílios sem a presença de pessoas idosas e com tutor que possui hábito saudável em relação ao seu próprio consumo de guloseimas apresentou maior associação com animais em condição corporal ideal e, perfil D: residências com idosos e com tutores praticantes de hábitos não saudáveis em relação ao seu próprio consumo de guloseimas apresentaram maior associação com cães em sobrepeso ou obesos. 
Figura 1 - Análise de correspondência múltipla da relação entre a classificação do escore de condição corporal (ECC) dos cães e caraterísticas significativas na análise simples. São Paulo SP, 2019.

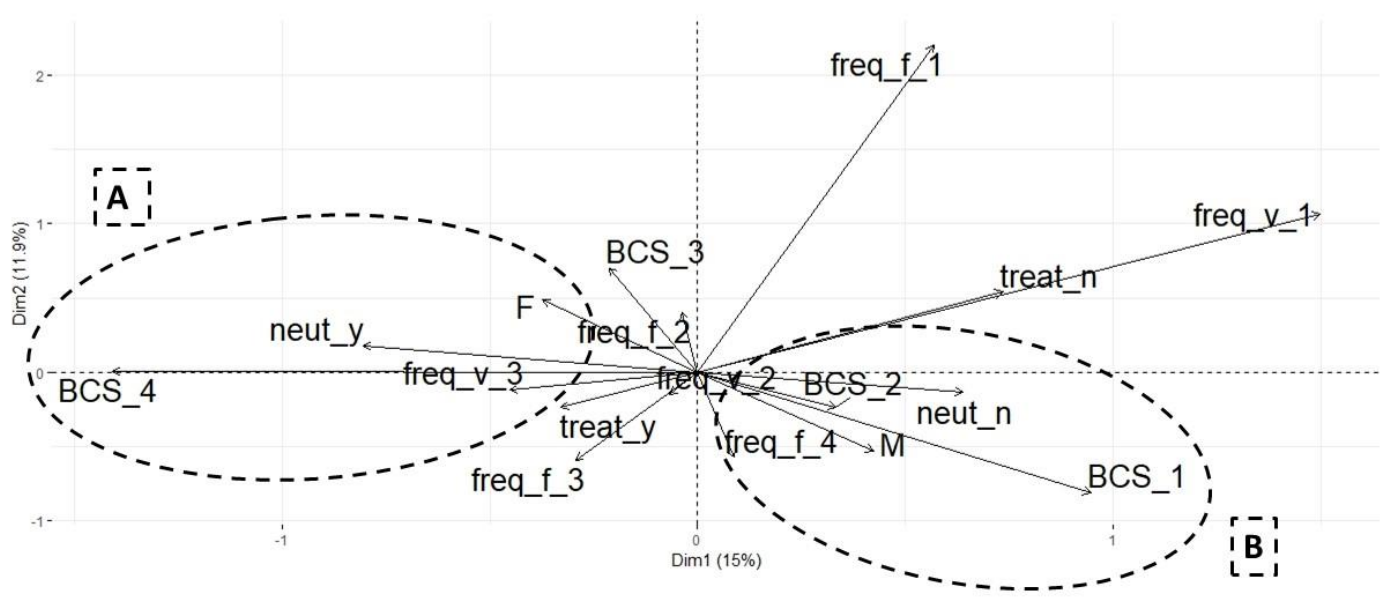

Legenda: BCS_1: abaixo do peso; BCS_2: ideal; BCS_3: sobrepeso; BCS_4: obeso; F: fêmea; M=macho; neut_y: castrados; neut_n: não castrados; freq._f_1: frequência alimentar de 1 vez ao dia; freq._f2: frequência alimentar de $\overline{2}$ vezes ao dia, freq._f_3: frequência alimentar de 3 vezes ao dia; freq.___4: alimentação ad libitum; freq._v_1: nunca foram ao médico veterinário; freq._v_2: só vão ao médico veterinário quando doentes; freq._v_3: comparecem com frequência ao médico veterinário; treat_y=recebem petiscos; treat_n: não recebem petiscos. 
Figura 2 - Análise de correspondência múltipla da relação entre a classificação do escore de condição corporal (ECC) com as variáveis significativas em relação ao tutor na análise simples. São Paulo - SP, 2019.

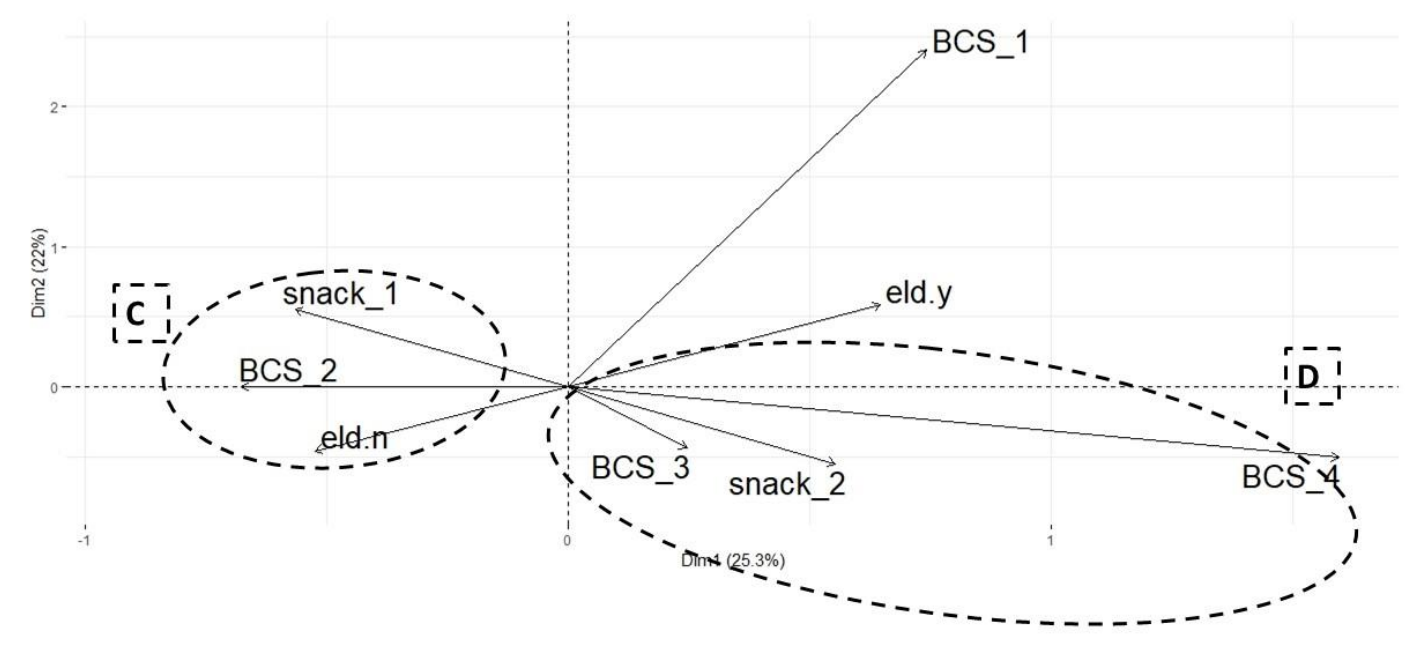

Legenda: BCS_1: abaixo do peso; BCS_2: condição corporal ideal; BCS_3: sobrepeso; BCS_4: obeso; eld_y: domicílio com presença de idosos; eld_n: domicílio sem presença de idosos; snack_1: hábitos saudáveis em relação ao consumo de guloseimas; snack_2= hábitos não saudáveis em relação ao consumo de guloseimas.

\subsection{Análise de regressão logística múltipla}

Para definição das chances do animal se tornar obeso ou em sobrepeso em relação aos animais em condição corporal ideal, realizou-se a análise de regressão logística múltipla (Tabela 12). Algumas características dos animais apresentaram associação à maiores chances dos cães atingirem o sobrepeso ou se tornarem obeso, como as fêmeas que apresentaram 2,45 mais chances e animais castrados, independente do sexo, que tiveram 2,88 mais chances de ganharem peso.

Em relação aos moradores do domicílio, as chances foram 1,69 maiores nas casas que possuíam mais de um animal e 1,89 maiores dos animais ganharem peso nos domicílios com a presença de pessoas idosas.

Os dados verificados por análise de regressão logística múltipla (Tabela 13) apontaram que fêmeas, animais castrados e que dividem residências com pessoas idosas e/ou com outros animais, apresentaram maiores chances de desenvolverem condição corporal acima do ideal. 
Tabela 12 - Análise de regressão logística múltipla dos animais avaliados no estudo, divididos em categorias de condição corporal. São Paulo - SP, 2019.

\begin{tabular}{|c|c|c|c|c|c|c|c|c|c|}
\hline \multirow[t]{2}{*}{ Variável } & \multicolumn{2}{|c|}{$\begin{array}{c}\text { Sobrepeso e } \\
\text { Obeso } \\
\text { (ECC } \geq 6)\end{array}$} & \multicolumn{2}{|c|}{$\begin{array}{c}\text { Ideal } \\
(\text { ECC } 4 \text { e } 5)\end{array}$} & \multicolumn{2}{|c|}{ Total } & \multirow[t]{2}{*}{ OR } & \multirow[t]{2}{*}{ IC 95} & \multirow[t]{2}{*}{ Valor $p$ - } \\
\hline & $\mathbf{N}$ & $\%$ & $\mathbf{N}$ & $\%$ & $\mathbf{N}$ & $\%$ & & & \\
\hline \multicolumn{10}{|c|}{ Sexo } \\
\hline Fêmea & 74 & 53,2 & 65 & 46,8 & 139 & 100,0 & 2,45 & $1,48-4,06$ & $<0,001$ \\
\hline Macho & 39 & 31,7 & 84 & 68,3 & 123 & 100,0 & & & \\
\hline \multicolumn{10}{|c|}{ Faixa etária } \\
\hline Jovem & 59 & 37,6 & 98 & 62,4 & 157 & 100,0 & 0,57 & $0,34-0,94$ & 0,020 \\
\hline Adulto & 51 & 51,5 & 48 & 48,5 & 99 & 100,0 & & & \\
\hline \multicolumn{10}{|c|}{ Status reprodutivo } \\
\hline Sim & 67 & 57,3 & 50 & 42,7 & 117 & 100,0 & 2,88 & $1,74-4,78$ & $<0,001$ \\
\hline Não & 46 & 31,7 & 99 & 68,3 & 145 & 100,0 & & & \\
\hline \multicolumn{10}{|c|}{ Idade de castração } \\
\hline Até 3 anos & 43 & 53,1 & 38 & 46,9 & 81 & 100,0 & 0,38 & $0,14-1,05$ & 0,050 \\
\hline Acima de 3 anos & 18 & 75,0 & 6 & 25,0 & 24 & 100,0 & & & \\
\hline \multicolumn{10}{|c|}{ Frequência alimentar } \\
\hline Até 3 vezes & 57 & 44,2 & 72 & 55,8 & 129 & 100,0 & 1,13 & $0,69-1,85$ & 0,360 \\
\hline A vontade & 54 & 41,2 & 77 & 58,8 & 131 & 100,0 & & & \\
\hline \multicolumn{10}{|c|}{ Quantificação do alimento } \\
\hline Inespecífica & 93 & 43,5 & 121 & 56,5 & 214 & 100,0 & 1,19 & $0,62-2,29$ & 0,356 \\
\hline Pesada & 18 & 39,1 & 28 & 60,9 & 46 & 100,0 & & & \\
\hline \multicolumn{10}{|c|}{ Atividade física } \\
\hline Pratica & 8 & 27,6 & 21 & 72,4 & 29 & 100,0 & 0,71 & $0,22-2,33$ & 0,398 \\
\hline Não pratica & 8 & 34,8 & 15 & 65,2 & 23 & 100,0 & & & \\
\hline \multicolumn{10}{|c|}{ Classificação do índice de massa corporal do tutor } \\
\hline Sobrepeso/obeso & 60 & 41,1 & 86 & 58,9 & 146 & 100,0 & 0,86 & $0,53-1,42$ & 0,328 \\
\hline Magro/ideal & 50 & 44,6 & 62 & 55,4 & 112 & 100,0 & & & \\
\hline \multicolumn{10}{|c|}{ Fornecimento de petiscos } \\
\hline Sim & 84 & 45,2 & 102 & 54,8 & 186 & 100,0 & 1,33 & $0,77-2,30$ & 0,184 \\
\hline Não & 29 & 38,2 & 47 & 61,8 & 76 & 100,0 & & & \\
\hline \multicolumn{10}{|c|}{ Contactantes } \\
\hline Sim & 64 & 49,6 & 65 & 50,4 & 129 & 100,0 & 1,69 & $1,03-2,76$ & 0,025 \\
\hline Não & 49 & 36,8 & 84 & 63,2 & 133 & 100,0 & & & \\
\hline \multicolumn{10}{|c|}{ Local de moradia } \\
\hline Apartamento & 30 & 41,7 & 42 & 58,3 & 72 & 100,0 & 092 & $052 \quad 150$ & 0140 \\
\hline Casa & 83 & 43,7 & 107 & 56,3 & 190 & 100,0 & & & \\
\hline
\end{tabular}


Tabela 12 continua...

\begin{tabular}{lccccccccc}
\hline & \multicolumn{8}{c}{ Presença de crianças } \\
Sim & 31 & 44,9 & 38 & 55,1 & 69 & 100,0 & 1,01 & $0,58-1,76$ & 0,546 \\
Não & 81 & 44,8 & 100 & 55,2 & 181 & 100,0 & & & \\
& \multicolumn{8}{c}{ Presença de idoso } \\
Sim & 58 & 53,7 & 50 & 46,3 & 108 & 100,0 & 1,89 & $1,14-3,14$ & 0,014 \\
Não & 54 & 38,0 & 88 & 62,0 & 142 & 100,0 & & & \\
\hline
\end{tabular}

Legenda: ECC: escore de condição corporal; OR: Odds ratio.

Tabela 13 - Análise de regressão logística múltipla de cães em sobrepeso e obesos. São Paulo - SP, 2019.

\begin{tabular}{lcccc}
\hline Variável & OR ajustado & IC 95\% & p-valor & R quadrado \\
\hline Castrados & 3,03 & $1,75-5,24$ & $<0,001$ & \\
Fêmeas & 2,46 & $1,42-4,25$ & 0,001 & 0,204 \\
Presença de idoso & 1,79 & $1,04-3,12$ & 0,036 & \\
Contactantes & 1,88 & $1,09-3,26$ & 0,024 &
\end{tabular}

Legenda: OR: Odds ratio. 


\section{DISCUSSÃO}

A prevalência de sobrepeso e obesidade dos cães domiciliados no município de São Paulo- SP encontrada no presente estudo foi de $40,5 \%$, resultados estes similares aos observados em estudos relativamente recentes realizados no Reino Unido, Japão, China e Espanha, que caracterizaram esta população entre 30 a 60\% (COURCIER et al., 2010; MAO et al., 2013; USUI et al., 2016; ALONSO et al., 2017). No entanto, vale ressaltar que os demais estudos avaliaram cães atendidos em clínicas e hospitais veterinários, diferente do presente estudo, no qual os cães foram abordados em suas próprias residências. Esta abordagem permitiu com que animais que nunca haviam sido atendidos por médicos veterinários fossem também avaliados, o que garante de certa forma uma população de estudo com menor viés.

Diversos fatores já foram citados como predisponentes à obesidade canina, dos quais podem ser destacados o sexo, raça e status reprodutivo, além de hábitos associados ao manejo e aos tutores (GERMAN, 2006; COURCIER et al., 2010; LARSEN; VILLAVERDE, 2016; CHANDLER et al., 2017). No presente estudo, a maioria dos cães em sobrepeso e obesos foram representados por animais do sexo feminino. Essa observação corroborou os resultados encontrados por outros autores (MASONE, 1970; EDNEY; SMITH, 1986; MCGREEVY et al., 2005; COLLIARD, 2006; COURCIER et al., 2010; MAO et al., 2013) os quais apontaram que as fêmeas são mais predispostas ao excesso de peso. Além disso, as chances dos animais apresentarem condição corporal acima do ideal foram 2,45 vezes maiores nas fêmeas, em comparação aos machos, como também encontrado por Edney; Smith (1986). Essa associação pode ser justificada pelo fato das fêmeas apresentarem menor taxa metabólica basal, além dos efeitos do hormônio estrógeno (KIL; SWANSON, 2010).

A castração vem sendo referida em inúmeros estudos como fator associado ao excesso de peso dos cães (ROBERTSON, 2003; GERMAN, 2006; COURCIER et al., 2010; MAO et al., 2013; KAWAUCHI et al., 2017; MUNOZ-PRIETO et al., 2018). No presente estudo, este fator independente do sexo, também apresentou associação com a condição corporal dos animais, além de representar 2,88 mais chances dos animais se tornarem obesos ou em sobrepeso. Esse fato pode ser justificado pela redução do metabolismo basal já caracterizado em animais castrados, ocasionado pela redução da necessidade energética, aumento da 
quantidade de gordura corporal e aumento da ingestão alimentar (ROBERTSON, 2003; COLLIARD et al., 2006; BERMINGHAM et al., 2014; KAWAUCHI et al., 2017). Contudo, alguns autores já relataram que a castração, quando realizada de forma precoce, pode favorecer a manutenção da condição corporal (SALMERI; OLSON; BLOOMBERG, 1991; SPAIN; SCARLETT; HOUPT, 2004). No presente estudo, não houve associação entre a idade da castração e a condição corporal dos animais. Porém, quando considerados animais castrados após três anos de idade, observouse tendência a maiores chances desses animais mudarem sua condição corporal para acima do ideal (sobrepeso ou obesos).

Outro fator também associado à redução do metabolismo é o envelhecimento, que além de alterar o gasto energético diário, reduz a disposição para a prática de atividade física, fato este importante na prevenção da obesidade (HARPER, 1998). Muitos trabalhos demonstraram que o sobrepeso e obesidade estão presentes em animais de meia idade e idosos (MASON, 1970; MCGREEVY et al., 2005; WEETH et al., 2006; MAO et al., 2013; LUND et al., 2015; USUI; YASUDA; KOKETSU, 2016). No presente estudo, embora esse fator não tenha sido associado ao ECC dos cães, a prevalência de sobrepeso e obesidade foi maior na faixa etária de meia idade.

Algumas raças, tais como Beagle, Dachshund, Golden Retriever e Labrador Retriever, foram descritas como mais susceptíveis à obesidade (EDNEY; SMITH 1986; KRONFELD; DONOGHUE; GLICKMAN, 1991; USUI; YASUDA; KOKETSU, 2016). No presente estudo, os animais com maior prevalência de sobrepeso e obesidade foram aqueles sem raça definida. Este fato pode ser explicado pela menor representatividade das demais raças na população ora estudada, o que não possibilitou a detecção desta associação. Contudo, quando observado os cães da raça Labrador Retriever pôde-se notar que $70,0 \%$ deles estavam acima do peso, diferente dos cães da raça Shih-tzu, que em sua maioria $(81,2 \%)$ apresentaram condição corporal ideal. Essa informação pode ser justificada pela presença do gene da pró-opiomelanocortina (POMC) descrito anteriormente nos cães da raça Labrador Retriever, que está associado ao apetite voraz e ao risco de obesidade (RAFFAN et al., 2016; DAVISON et al., 2017).

O manejo alimentar relaciona-se de forma direta com a condição corporal do animal, seja em relação à frequência de alimentação, escolha do alimento ou o modo de quantificá-lo (BROOKS et al., 2014). Alguns estudos epidemiológicos 
referem que o manejo ideal para controle de peso consiste em alimentar os cães várias vezes ao dia, em pequenas quantidades, com intuito de aumentar a perda de energia por termogênese (ROBERTSON, 2003; COLLIARD et al. 2006). No presente estudo, assim como também referido por Bland et al. (2009) e Mao et al. (2013), esta associação não foi observada, visto que a obesidade foi relacionada ao consumo de alimentos em frequência igual ou superior a três vezes ao dia.

Outro fator que pode influenciar no consumo de calorias ingeridas pelo animal é a escolha do tipo de alimento fornecido (BROOKS et al., 2014). Segundo estudo epidemiológico realizado por Mao et al. (2013), o consumo de alimentos comerciais foi associado à menor prevalência de obesidade, diferente do observado no presente estudo, que apesar de não ter sido encontrada associação entre a condição corporal e o tipo de alimentação, a maioria (71,7\%) dos animais acima da condição corporal ideal recebiam alimento comercial extrusado. O mercado de pet food apresenta vasta diversidade de produtos comerciais para cães com diferentes concentrações de energia. Assim, para se analisar o consumo energético dos animais, é necessário que além de se considerar o tipo de alimento, também se leve em conta a quantidade ingerida. Nesse estudo, não foi possível realizar essa avaliação em virtude da maioria dos tutores fornecer alimento ad libitum.

O método de alimentação ad libitum para cães é muito comum pela praticidade desse manejo no momento da alimentação (GERMAN, 2006; MAO et al., 2013). No entanto, este hábito pode resultar em consequências como excesso de consumo alimentar, principalmente em domicílios com mais de um animal, pois a competição pode aumentar o consumo de alimentos ou permitir que o cão ingira 0 alimento do contactante e o seu. Com base nos dados levantados no presente estudo, foi possível verificar que a presença de outro cão na mesma casa, aumentou em 1,69 vezes as chances de desenvolvimento de sobrepeso ou obesidade.

Além do consumo da dieta de base, a ingestão de petiscos também foi associada ao ganho de peso dos cães (BLAND; HILL, 2012; LARSEN; VILLAVERDE, 2016). Na maioria das vezes, o consumo dessas guloseimas pode exceder a necessidade energética diária devido ao seu incremento calórico (MASON, 1970; ROBERTSON, 2003; LUND et al., 2006; GERMAN et al., 2010; ZORAN, 2010; ALONSO et al., 2017). Tal informação foi confirmada neste estudo, pois houve associação entre a ingestão de petiscos e maior ECC dos cães. 
Um fato interessante é que embora já tenha sido apontado por outros autores que fatores relacionados aos tutores podem ser transferidos aos seus animais (COURCIER et al., 2010; BLAND et al., 2009), escassos foram os estudos que associaram os hábitos alimentares dos proprietários com os de seus cães. No presente estudo houve associação entre consumo de guloseimas pelos tutores com o ECC dos cães. Assim, os tutores de cães acima do peso em sua maioria $(73,7 \%)$ também possuiam hábitos não saudáveis em relação a esse comportamento. No entanto, esses mesmos proprietários referiram bom padrão alimentar em relação ao consumo de frutas e legumes e, este aspecto não foi associado à condição corporal desses cães. Vale ressaltar que, embora os tutores tenham informado possuir bom padrão alimentar no consumo desses alimentos, a maior parte das pessoas avaliadas estavam acima do peso e apresentavam riscos de doenças metabólicas. Isto sugere possível viés involuntário, visto que esses alimentos já foram indicados como indispensáveis para a saúde em estudo brasileiro sobre a percepção de consumo alimentar (MOURA; MASQUIO, 2014). Este viés se refere ao possível comportamento defensivo diante de algumas perguntas, por alguns respondentes, e o receio de julgamento pode fazer com que omitam informações que não julguem corretas (SELLTIZ; WRIGHTSMAN; COOK, 1981).

Diferente do observado em estudos epidemiológicos realizados na França, Estados Unidos e Espanha, nos quais a condição corporal dos tutores foi associada com a de seus cães (COLLIARD, 2006; BLAND et al., 2009; ALONSO et al., 2017). $E$ estudo que avaliou crianças obesas e observou associação entre a condição corporal dessas com de seus pais (RAMOS; BARROS FILHO, 2003). No presente estudo, essa associação não foi encontrada e, nem às chances do animal desenvolver obesidade, esse fato pode ser justificado pela a alta incidência de excesso de peso dos proprietários participantes.

Muitos indivíduos não reconhecem a própria condição corporal e nem a de seus filhos, o que é caracterizado como um problema na medicina humana, pois quando a obesidade não é reconhecida, medidas profiláticas e corretivas não são tomadas (KUCHLER; VARIYAM, 2002; TENORIO;COBAYASHI, 2011). Na medicina veterinária, esse fato também já foi citado em trabalhos anteriores e pôde ser demonstrado nesse estudo, no qual muitos tutores subestimaram ou superestimaram a condição corporal de seus cães, além de classificarem cães abaixo do peso e em sobrepeso como em condição corporal ideal e, obesos como 
apenas em sobrepeso (BLAND et al., 2010; TEIXEIRA et al., 2015). Isso faz com que muitos médicos veterinários resistam em informar ao tutor que seu cão está obeso, provavelmente por receio de irritar ou mesmo perder o cliente devido a não aceitação desta condição (BARTGES et al., 2017).

Por outro lado, o médico-veterinário tem como uma de suas atribuições o papel de orientar o tutor sobre a condição corporal do seu cão, assim como o manejo nutricional, discutir opções de alimentos e determinar a quantidade apropriada a ser fornecida a cada paciente (BALDWIN et al., 2010; HEUBERGER; WAKSHLAG, 2011). Assim sendo, uma recomendação nutricional adequada deve levar em consideração idade, nível de atividade física, a individualidade do animal, entre outros fatores (BROOKS et al., 2014; CHURCHILL; WARD, 2016). Em estudo realizado na Alemanha, os autores observaram que os tutores buscavam o médicoveterinário para receber orientações sobre a forma correta de alimentar seus cães (KIENZLE; BERGLER; MANDERNACH, 1998). No entanto, esse cuidado não foi observado em relação aos tutores paulistanos avaliados no presente estudo, no qual pôde-se constatar que a maioria deles não seguiam as recomendações de quantidade de alimento apresentadas no rótulo do produto ou do médico-veterinário na hora de escolher ou quantificar o alimento de seus cães.

A baixa procura por atendimento veterinário pode estar relacionada ao manejo alimentar errôneo praticado pela maioria dos tutores de cães acima do peso, uma vez que esses referiram procurar atendimento por esses profissionais somente quando o animal apresentava alguma alteração clínica. Contudo, a maioria dos tutores realizou a imunização profilática anual no médico-veterinário. Portanto, esse momento poderia ser utilizado para a conscientização dos tutores frente ao ECC dos cães e o correto manejo alimentar.

Um dos fatores que contribui para a manutenção de peso e prevenção de obesidade é a prática regular de atividade física (ROBERTSON, 2003; BLAND et al., 2009; GERMAN et al., 2017). Nesse estudo, embora não tenha sido observada associação entre a prática de exercício físico e a condição corporal dos animais, a parcela da população de cães classificadas como sobrepeso e obesos foram considerados sedentários por seus tutores. Um dos principais motivos que pode levar os tutores a restringirem a prática de atividade física de seus cães são complicações na saúde desses animais, tais como alterações locomotoras ou respiratórias que podem dificultar o exercício (GERMAN et al., 2012; HOENIG, 
2014). No entanto, essas possíveis limitações descritas na literatura não justificam o sedentarismo observado nos cães do presente estudo, visto que a maioria deles eram saudáveis. Outra hipótese para a baixa frequência de atividade física observada pelos animais aqui avaliados pode estar associada a baixa frequência de exercícios de seus tutores, que uma vez sedentários, tendem a possuir cães também sedentários.

Ademais, restrições referentes aos tutores também podem justificar 0 sedentarismo dos cães, dentre elas a faixa etária dos mesmos, pois já foi descrito em estudo que a maioria das pessoas idosas não realizavam atividade física por desinteresse e complicações relacionadas à idade (CARVALHO et al., 2017). No presente estudo, a maioria das casas com presença de pessoas idosas possuíam cães obesos e, esse fator foi relacionado com o maior ECC dos animais. Além disso, esse fato culminou no aumento de 1,89 vezes nas chances do animal desenvolver sobrepeso ou obesidade. A observação de que moradores idosos estão mais associados a serem tutores de cães com condição corporal acima do ideal também já foi apontada em estudos epidemiológicos realizados no Reino Unido e França (COLLIARD et al., 2006; COURCIER et al., 2010; MUNOZ-PRIETO et al., 2018). Além da restrição da prática de atividade física, por incapacitações resultantes do avançar da idade, outra hipótese que pode ser apontada em relação à faixa etária do tutor é o fato dos idosos passarem mais tempo com os animais, o que aumenta as chances de fornecimento de alimentos extras entre as refeições e assim, o maior consumo calórico (COLLIARD, 2006; BLAND et al., 2009; WHITE et al., 2011).

Estratégias que poderiam resultar em aumento da oportunidade de exercícios pelos cães incluem a presença de outros animais na casa, que estimulam a atividade física entre eles e, pátios ou espaços externos (ROBERTSON, 2003; COLLIARD et al., 2006; MAO et al., 2013). Seguindo essa premissa, seria esperado que a maioria dos animais acima do peso residisse em apartamentos ou espaços mais confinados. No entanto, isso não foi observado, diferente dos dados de estudos epidemiológicos realizados na França por Colliard et al. (2006) e na China por Mao et al. (2013). Todavia, no presente estudo, não foram referidos pelos tutores questões sobre a residência, tais como acesso do animal à área externa, quando presente e, o tamanho da moradia, o que pode ter gerado viés, pois foram visitados apartamentos com tamanho superior a diversas casas. 
A classe econômica e a escolaridade também já foram associadas ao padrão alimentar em pessoas, sendo os menos favorecidos financeiramente e com menor escolaridade os mais propensos a apresentarem padrão alimentar insuficiente e com menor consumo de alimentos de baixa densidade energética (MONTEIRO; CONDE, 2003; LEVY-COSTA et al., 2005; FERREIRA; MAGALHÃES, 2011; MALTA et al., 2014). Em cães, a classe socioeconômica dos tutores também já foi associada à obesidade canina. Um estudo realizado em 2010, com 696 cães, demonstrou que tutores em melhor situação financeira apresentavam probabilidade $62 \%$ menor de possuir animais obesos (COURCIER et al., 2010). No presente estudo, não houve associação entre esses dados, assim como também observado por Munoz-Prieto et al. (2018).

A determinação da obesidade e os fatores associados a ela podem auxiliar o médico-veterinário a abordar de maneira mais específica tutores de cães que apresentem maiores fatores de riscos. Nesse estudo, quando avaliados os fatores de riscos que apresentaram associação ao excesso de peso de forma conjunta, pôde-se notar que cães castrados que são assistidos com frequência pelo médicoveterinário foram mais associados com a condição corporal dos animais. Ademais, domicílios com a presença de idosos e tutores com hábito não saudável em relação ao consumo de guloseimas estão mais associados a possuírem cães em sobrepeso ou obesos. 


\section{CONCLUSÃO}

A prevalência de sobrepeso e obesidade canina observada no presente estudo foi de $40,5 \%$. Os fatores inerentes aos animais que influenciaram em sua condição corporal foram o sexo e status reprodutivo. Em relação ao manejo empregado aos cães, a frequência com que eram assistidos pelos médicos veterinários, assim como as práticas alimentares envolvendo a frequência alimentar e o consumo de petiscos foram associados a condição corporal dos cães. O local de moradia, assim como a presença de contactantes também foram associados a maiores chances dos animais ganharem peso. Fatores inerentes aos tutores como a presença de idosos no domicílio e o hábito não saudável em relação ao consumo de guloseima foram também associados ao ECC dos cães e a maiores chances dos animais se tornarem acima do peso. Ademais, o não reconhecimento dos tutores sobre a condição corporal dos seus animais também influenciou no ECC dos mesmos. 


\section{REFERÊNCIAS}

ABESO, 4.ed.Associação Brasileira para o Estudo da Obesidade e da Síndrome Metabólica. Diretrizes brasileiras de obesidade 2016 / ABESO - Associação Brasileira para o Estudo da Obesidade e da Síndrome Metabólica. - 4.ed. - São Paulo, SP

ALONSO, J. A.; BAUTISTA-CASTAÑO, I.; PEÑA, C.; SUÁREZ, L.; JUSTE, M. C.; TVARIJONAVICIUTE, A. Prevalence of Canine Obesity, Obesity-Related Metabolic Dysfunction, and Relationship with Owner Obesity in an Obesogenic Region of Spain. Frontiers in Veterinary Science, v. 4, n. 59, april, p. 2-5, 2017.

APTEKMANN, K. P.; MENDES-JUNIOR, A. F.; SUHETT, W. G.; GUBERMAN, U. C. Manejo nutricional de cães e gatos domiciliados no estado do Espírito Santo - Brasil. Arquivo Brasileiro de Medicina Veterinária e Zootecnia, v. 65, n. 2, p. 455-459, november, 2013.

BARTGES, J.; KUSHNER, R. F.; MICHEL, K. E.; SALLIS, R.; DAY, M. J. One Health Solutions to Obesity in People and Their Pets. Journal of Comparative Pathology, v. 156, n. 4, p. 326-333, may, 2017.

BERMINGHAM, E. N.; THOMAS, D. G.; CAVE, N. J.; MORRIS, P. J.; BUTTERWICK, R. F.; GERMAN, A. J. Energy Requirements of Adult Dogs: A MetaAnalysis. PloS one, v. 9, n. 10, p. e109681-e109681, octuber, 2014.

BLAND, I. M.; GUTHRIE-JONES, A.; TAYLOR, R. D.; HILL, J. Dog Obesity: Owner Attitudes and Behaviour. Preventive veterinary medicine, v. 92, n. 4, p. 333-340, dez. 2009. 
BLAND, I. M.; GUTHRIE-JONES, A.; TAYLOR, R. D.; HILL, J. Dog Obesity: Veterinary Practices' and Owners' Opinions on Cause and Management. Preventive Veterinary Medicine, v. 94, n. 3-4, p. 310-315, may., 2010.

BRAY GA, GRAY DS. Obesity. Part I - Pathogenesis. Western Journal of Medicine, 149:429-441. Oct., 1988.

BROOKS, D.; CHURCHILL, J.; FEIN, K.; LINDER, D.; MICHEL, K. E.; TUDOR, K.; WARD, E.; WITZEL, A. 2014 AAHA Weight Management Guidelines for Dogs and Cats $^{*}$. Journal of the American Animal Hospital Association, v. 50, n. 1, p. 111,2014

BRUNETTO, M. A.; NOGUEIRA, S.; SÁ, F. C.; PEIXOTO RICARDO SOUZA VASCONCELLOS, M.; FERRAUDO, A. J.; CARCIOFI, A. C. Correspondence between obesity and hyperlipidemia in dogs . Ciencia Rural, v. 41, n. 2, p. 266-271, 2011.

BRUNETTO, M. A.; SÁ, F. C.; NOGUEIRA, S. P.; GOMES, M. de O. S.; PINAREL, A. G.; JEREMIAS, J. T.; DE PAULA, F. J. A.; CARCIOFI, A. C. The intravenous glucose tolerance and postprandial glucose tests may present different responses in the evaluation of obese dogs. The British Journal of Nutrition, v. 106 Suppl, p. S194-7, out. 2011b.

BURGER, I. H.; JOHNSON, J. V. Dogs large and small: the allometry of energy requirements within a single species. The Journal of nutrition, v. 121, n. 1, p. S18S21, september, 1991. 
CANATTO, B. D.; SILVA, E. A.; BERNARDI, F.; MENDES, M. C. N. C.; PARANHOS, N. T.; DIAS, R. A. Demographic characterization of supervised dog and cat populations in Sao Paulo city, Brazil. Arq. Bras. Med. Vet. Zootec, v. 64, n. 6, p. 1515-1523, September,2012.

CARVAlho, B. A. F.; SANTOS, M. A. P.; NOGUEIRA, F. R. S.; SÁ, G. G. M.; OLIVEIRA NETO, J. G.; MARTINS, M. C. C, SANTOS, E. P. Prevalence exercises physical practice in the elderly and its relationship with the difficulties and counseling lack of professional specific. R. bras. Ci. e Mov, v. 25, n. 1, p. 29-40, november 2017.

CHANDLER, M. L. Impact of Obesity on Cardiopulmonary Disease. Veterinary Clinics of North America - Small Animal Practice, v. 46, n. 5, p. 817-830, 2016.

CHANDLER, M.; CUNNINGHAM, S.; LUND, E. M.; KHANNA, C.; NARAMORE, R.; PATEL, A.; DAY, M. J. Obesity and associated comorbidities in people and companion animals: A One Health Perspective. Journal of Comparative Pathology, v. 156, n. 4, p. 296-309, may, 2017.

CLARK, M.; HOENIG, M. Metabolic Effects of Obesity and Its Interaction with Endocrine Diseases. The Veterinary clinics of North America. Small animal practice, v. 46, n. 5, p. 797-815, set. 2016.

COLLIARD, L.; ANCEL, J.; BENET, J.-J.; PARAGON, B. M.; BLANCHARD, G. Risk Factors for Obesity in Dogs in France. The Journal of nutrition, v. 136, p. 1951S1954S, july, 2006. 
CORBEE, R. J. Obesity in Show Dogs. Journal of animal physiology and animal nutrition, v. 97, n. 5, p. 904-910, out. 2013.

COURCIER, E. A.; O'HIGGINS, R.; MELLOR, D. J.; YAM, P. S. Prevalence and risk factors for feline obesity in a first opinion practice in Glasgow, Scotland. Journal of Feline Medicine and Surgery, v. 12, n. 10, p. 746-753, july, 2010.

CROFT, J,B.; KEENAN, N.L.; SHERIDAN, D.P.; WHEELER, F.C.; SPEERS, M. A. Waist-to-hip ratio in a biracial population: measurement, implications, and cautions for using guidelines to define high risk for cardiovascular disease. J Am Diet Assoc. v. 95. n. 1, p.60-4, jan.,1995.

DAVISON, L. J.; HOLDER, A.; CATCHPOLE, B.; O'CALLAGHAN, C. A. The Canine POMC Gene, Obesity in Labrador Retrievers and Susceptibility to Diabetes Mellitus. Journal of veterinary internal medicine, v. 31, n. 2, p. 343-348, mar. 2017.

DEGELING, C.; LINDSAY, B.; MCCORMACK, G. R. An Investigation of the Association between Socio-Demographic Factors, Dog-Exercise Requirements, and the Amount of Walking Dogs Receive. Canadian Journal of Veterinary Research, v. 76, n. 3, p. 235-240, july, 2012.

EDNEY, A. T.; SMITH, P. M. Study of obesity in dogs visiting veterinary practices in the United Kingdom. The Veterinary record, v. 118, n. 14, p. 391-6, 5, april. 1986.

FERREIRA, V. A.; MAGALHÃES, R. Obesity among the poor in Brazil: female vulnerability. Ciência \& Saúde Coletiva, v. 16, n. 4, p. 2279-2287, april, 2011. 
FLANAGAN, J.; BISSOT, T.; HOURS, M.-A.; MORENO, B.; FEUGIER, A.; GERMAN, A. J. Success of a weight loss plan for overweight dogs: The results of an international weight loss study. PLoS ONE, v. 12, n. 9, p. 1-23, sept., 2017.

FREEMAN, L. M.; ABOOD, S. K.; FASCETTI, A. J.; FLEEMAN, L. M.; MICHEL, K. E.; LAFLAMME, D. P.; BAUER, C.; KEMP, B. L. E.; VAN DOREN, J. R.; WILLOUGHBY, K. N. Disease prevalence among dogs and cats in the United States and Australia and proportions of dogs and cats that receive therapeutic diets or dietary supplements. Journal of the American Veterinary Medical Association, v. 229, n. 4, p. 531-4, august, 2006.

GARVEY, W. T.; MECHANICK, J. I.; BRETT, E. M.; GARBER, A. J.; HURLEY, D. L.; JASTREBOFF, A. M.; NADOLSKY, K.; PESSAH-POLLACK, R.; PLODKOWSKI, R. AACE / ACE Guidelines American association of clinical endocrinologists and american college of endocrinology comprehensive clinical practice guidelines for medical care of patients with obesity, Endocrine Practice v. 22, n. july, 2016.

GERMAN, A. J. The WALTHAM International Nutritional Sciences Symposia. The Growing Problem of Obesity in Dogs and Cats. J. Nutr, v. 136, n. 7 Suppl, p. 19401946, 2006.

GERMAN, A. J.; BLACKWELL, E.; EVANS, M.; WESTGARTH, C. Overweight Dogs Exercise Less Frequently and for Shorter Periods: Results of a Large Online Survey of Dog Owners from the UK. Journal of nutritional science, v. 6, p. e11,. April, 2017.

GERMAN, A. J.; HOLDEN, S. L.; WISEMAN-ORR, M. L.; REID, J.; NOLAN, A. M.; BIOURGE, V.; MORRIS, P. J.; SCOTT, E. M. Quality of life is reduced in obese dogs but improves after successful weight loss. Veterinary Journal, v. 192, n. 3, p. 428- 
434,. Jun., 2012.

GERMAN, A. J.; RYAN, V. H.; GERMAN, A. C.; WOOD, I. S.; TRAYHURN, P. Obesity, Its Associated Disorders and the Role of Inflammatory Adipokines in Companion Animals. Veterinary journal (London, England: 1997), v. 185, n. 1, p. 4-9, jul. 2010.

GONZÁLEZ RAMÍREZ, M. T.; LANDERO HERNÁNDEZ, R. Benefits of dog ownership: Comparative study of equivalent samples. Journal of Veterinary Behavior: Clinical Applications and Research, v. 9, n. 6, p. 311-315, december, 2014.

GREER, K. A.; CANTERBERRY, S. C.; MURPHY, K. E. Statistical analysis regarding the effects of height and weight on life span of the domestic dog. Research in Veterinary Science, v. 82, n. 2, p. 208-214, june, 2007.

HARPER, E. J. The WALTHAM International Nutritional Sciences Symposia. Changing perspectives on aging and energy requirements: Aging, body weight and body composition in humans, dogs and cats. J. Nutr., v. 128, n. 12 SS, p. S2627S2631, 1998.

HOENIG, M. Comparative Aspects of Human, Canine, and Feline Obesity and Factors Predicting Progression to Diabetes. Veterinary Sciences, v. 1, n. 2, p. 121135, august, 2014.

HOSGOOD, G.; SCHOLL, D. Evaluation of Age as a Risk Factor for Perianesthetic Morbidity and Mortality in the Dog. The Journal of Veterinary Emergency and Critical Care, v. 8, n. 3, p. 222-236, december, 1998. 
HUCK, J. L.; BIERY, D. N.; LAWLER, D. F.; GREGOR, T. P.; RUNGE, J. J.; EVANS, R. H.; KEALY, R. D.; SMITH, G. K. A longitudinal study of the influence of lifetime food restriction on development of osteoarthritis in the canine elbow. Veterinary Surgery, v. 38, n. 2, p. 192-198, feb., 2009.

HUANG, K. C.; LIN, W. Y.; LEE, L. T.; CHEN, C. Y.; LO, H.; HSIA, H. H.; LIU, I, L.; SHAU, W. Y.; LIN, R. S. Four anthropometric indices and cardiovascular risk factors in Taiwan. International Journal of Obesity and Related Metabolic Disorders. v. 26 , n. 8, p.1060-8, august, 2002;

JERICÓ, M.; SCHEFFER, K. Aspectos epidemiológicos dos cães obesos na cidade de São Pa | Revista Clínica Veterinária. Revista Clínica Veterinária, p. 25-29, março/abril, 2002.

JEUSETTE, I.; DETILlEUX, J.; CUVELIER, C.; ISTASSE, L.; DIEZ, M. Ad Libitum Feeding Following Ovariectomy in Female Beagle Dogs: Effect on Maintenance Energy Requirement and on Blood Metabolites. Journal of animal physiology and animal nutrition, v. 88, n. 3-4, p. 117-121, april. 2004.

JeUsetTE, I.; GRECO, D.; AQUino, F.; DETIlleUX, J.; PETERSON, M.; ROMANO, V.; TORRE, C. Effect of breed on body composition and comparison between various methods to estimate body composition in dogs. Research in Veterinary Science, v. 88, n. 2, p. 227-232, july, 2010.

KAWAUCHI, I. M.; JEREMIAS, J. T.; TAKEARA, P.; DE SOUZA, D. F.; BALIEIRO, J. C. D. C.; PFRIMER, K.; BRUNETTO, M. A.; PONTIERI, C. F. F. Effect of dietary protein intake on the body composition and metabolic parameters of neutered dogs. Journal of Nutritional Science, p. 1-5, june, 2017. 
KEALY, R. D.; LAWLER, D. F.; BALLAM, J. M.; MANTZ, S. L.; BIERY, D. N.; GREELEY, E. H.; LUST, G.; SEGRE, M.; SMITH, G. K.; STOWE, H. D. Effects of diet restriction on life span and age-related changes in dogs. Journal of the American Veterinary Medical Association, v. 220, n. 9, p. 1315-1320, may, 2002.

KIENZLE, E.; BERGLER, R.; MANDERNACH, A. A Comparison of the Feeding Behavior and the Human-Animal Relationship in Owners of Normal and Obese Dogs. The Journal of nutrition, v. 128, n. 12 Suppl, p. 2779S-2782S, dec. 1998.

KIENZLE, E.; SCHRAG, I.; BUTTERWICK, R.; OPITZ, B. Calculation of Gross Energy in Pet Foods: Do We Have the Right Values for Heat of Combustion. JN The Journal of Nutrition, v. 132, p. 1799S-1800S, june, 2002.

KRONFELD, D. S.; DONOGHUE, S.; GLICKMAN, L. T. Body Condition and Energy Intakes of Dogs in a Referral Teaching Hospital. The Journal of nutrition, v. 121, n. 11 Suppl, p. S157-8, nov. 1991.

KROOK, L.; LARSSON, S.; ROONEY, J. R. The Effects of Obesity, Pyometra and Diabetes Mellitus on the Fat and Cholesterol Contents of Liver and Spleen in the Dog. Acta physiologica Scandinavica, v. 49, p. 29-34, may, 1960.

KUCHLER, F.; VARIYAM, J. N. Misperceptions in Self-Assessed Weight Status Vary Along Demographic Lines. FoodReview, p. 21-27, dec., 2002.

LAFLAMME, D. Development and validation of a body condition score system for dogs. Canine practice, v. 22, n. 4, p. 10-15, july/august., 1997. 
LANDIS, J. R.; KOCH, G. G. The Measurement of Observer Agreement for Categorical Data Data for Categorical of Observer Agreement The Measurement. Biometrics, v. 33, n. 1, p. 159-174, marc., 1977.

LAUTEN, S. D.; COX, N. R.; BRAWNER, W. R.; BAKER, H. J. Use of dual energy xray absorptiometry for noninvasive body composition measurements in clinically normal dogs. American journal of veterinary research, v. 62, n. 8, p. 1295-301, sept., 2001.

LEVY-COSTA, R. B.; SICHIERI, R.; PONTES, N. dos S.; MONTEIRO, C. A. Household food availability in Brazil: distribution and trends (1974-2003). Revista de saúde publica, v. 39, n. 4, p. 530-540, august, 2005.

LIN, W.Y.; LEE, L.T.; CHEN, C.Y.; LO, H.; HSIA, H.H.; LIU, I.L.; LIN, R.S.; SHAU, W.Y.; HUANG, K.C. Optimal cut-off values for obesity: using simple anthropometric indices to predict cardiovascular risk factors in Taiwan. International Journal of Obesity and Related Metabolic Disorders. v. 26, n. 9, p.1232-8. 2002;

LUND, E. M. E. E. M. E.; ARMSTRONG, P. J.; KIRK, C. A.; KLAUSNER, J. S. Prevalence and Risk Factors for Obesity in Adult Dogs from Private US Veterinary Practices. The Journal of Applied Research in Veterinary Medicine, v. 4, n. 2, p. 177-186, jan., 2006.

LUND, H. S.; SAEVIK, B. K.; FINSTAD, O. W.; GRONTVEDT, E. T.; VATNE, T.; EGGERTSDOTTIR, A. V. Risk Factors for Idiopathic Cystitis in Norwegian Cats: A Matched Case-Control Study. Journal of Feline Medicine and Surgery, v. 18, n. 6, p. 483-491, may, 2015. 
MALTA, D. C.; ANDRADE, S. C.; CLARO, R. M.; BERNAL, R. T. I.; MONTEIRO, C. A. Evolução anual da prevalência de excesso de peso e obesidade em adultos nas capitais dos 26 estados brasileiros e no Distrito Federal entre 2006 e 2012. REV BRAS EPIDEMIOL SUPPL PeNSE, p. 267-276, fev., 2014.

MAO, J.; XIA, Z.; CHEN, J.; YU, J. Prevalence and Risk Factors for Canine Obesity Surveyed in Veterinary Practices in Beijing, China. Preventive veterinary medicine, v. 112, n. 3-4, p. 438-442, nov. 2013.

MARSHALL, W.; BOCKSTAHLER, B.; HULSE, D.; CARMICHAEL, S. A. Review of Osteoarthritis and Obesity: Current Understanding of the Relationship and Benefit of Obesity Treatment and Prevention in the Dog. Veterinary and comparative orthopaedics and traumatology : V.C.O.T, v. 22, n. 5, p. 339-345, Aug., 2009.

MASON, E. Obesity in Pet Dogs. The Veterinary record, v. 86, n. 21, p. 612-616, may, 1970.

MAWBY, D. I.; BARTGES, J. W.; DAVIGNON, A.; LAFLAMME, D. P.; MOYERS, T. D.; COTTRELL, T. Comparison of Various Methods for Estimating Body Fat in Dogs. J.Am.Anim Hosp.Assoc., v. 40, n. 2, p. 109-114, 2004.

MCGREEVY, P. D.; P.C., T.; PRIDE A., F.; T., G.; B., J. Prevalence of Obesity in Dogs Examined by Australian Veterinary Practices and the Risk Factors Involved. Veterinary Record, v. 156, n. 22, p. 695-702, may, 2005.

MELDRUM, D. R.; MORRIS, M. A.; GAMBONE, J. C. Obesity pandemic: causes, consequences, and solutions-but do we have the will? Fertility and Sterility, v. 107, n. 4, p. 833-839, april, 2017. 
MICHEL, K. E. Nutritional management of body weight. In: FASCETTI, A. J.; DELANEY, S. J. (Ed.). Applied Veterinary Clinical Nutrition. 1. ed. lowa: WileyBlackwell, 2012. p. 109-124.

MICHEL, K. E.; SORENMO, K.; SHOFER, F. S. Evaluation of Body Condition and Weight Loss in Dogs Presented to a Veterinary Oncology Service. Journal of veterinary internal medicine, v. 18, n. 5, p. 692-695, march, 2004.

MINISTÉRIO DA SAÚDE. Secretaria de Atenção à Saúde. Departamento de Atenção Básica.Guia alimentar para a população brasileira / Ministério da Saúde, Secretaria de Atenção à Saúde, Departamento de Atenção Básica. - 2. ed. Brasília: Ministério da Saúde, 2014. 156 p.

MONTEIRO, C. A.; CONDE, W. L. The changing relationship between education and risk of obesity in Brazil (1975-1997). Caderno de Saúde Pública, v. 19, n. 1, p. 6775, july, 2003.

MOURA, A. F.; MASQUIO, D. C. L. Healthy eating in the perception of beneficiaries of the Food Bank program - Healthy eating. Nutrire, v. 39, n. 2, p. 222-232, august, 2014.

MUNOZ-PRIETO, A.; NIELS, L. R.; DĄBROWSKI, R.; BJORNVAD, C. R.; SÖDER, J.; LAMY, E.; MONKEVICIENE, I.; LJUBIĆ, B. B.; VASIU, I.; SAVIC, S.; BUSATO, F.; YILMAZ, Z.; B, A. F.; TVARIJONAVICIUTE, A. European dog owner perceptions of obesity and factors associated with human and canine obesity. Scientific reports, v. 8, p. 13353, sept., 2018. 
NRC - NATIONAL RESEARCH COUNCIL, NRC. Nutrient requirements of dogs. Washington: National Academy Press, 398p, 2006.

ORGANIZAÇÃO MUNDIAL DA SAÚDE (OMS). Obesity and overweight. 2017. Disponível em: < http://www.who.int/mediacentre/factsheets/fs311/en/>. Acesso em: 20 nov. 2017.

OSTO, M.; LUTZ, T. A. Translational value of animal models of obesity - Focus on dogs and cats. European Journal of Pharmacology, v. 759, p. 240-252, march, 2015.

PEDRINELLI, V.; PORSANI, M. Y. H.; LIMA, D. M.; BRUNETTO, M. A. Predictive equations of maintenance energy requirement of healthy and chronically ill adult dogs. In: 22nd Congress of The European Society of Veterinary and Comparative (ESVCN), 2018, Munique, Alemanha. p. 236, 2018.

PEÑA, C.; SUÁREZ, L.; BAUTISTA, I.; MONTOYA, J. A.; JUSTE, M. C. Relationship between Analytic Values and Canine Obesity. Journal of Animal Physiology and Animal Nutrition, v. 92, n. 3, p. 324-325, jun, 2008.

PEREIRA-NETO, G. B.; BRUNETTO, M. A.; CHAMPION, T., ORTIZ, E., CARCIOFI, A. C.; CAMACHO, A. A. Avaliação da pressão arterial sistêmica em cães obesos: comparação entre os métodos oscilométrico e doppler ultrassônico. Pesquisa Veterinária Brasileira, v. 34, p. 87-91, 2014. 
RAFFAN, E.; DENNIS, R. J.; O'DONOVAN, C. J.; BECKER, J. M.; SCOTT, R. A.; SMITH, S. P.; WITHERS, D. J.; WOOD, C. J.; CONCI, E.; CLEMENTS, D. N.; SUMMERS, K. M.; GERMAN, A. J.; MELLERSH, C. S.; ARENDT, M. L.; IYEMERE, V. P.; WITHERS, E.; SÖDER, J.; WERNERSSON, S.; ANDERSSON, G.; LINDBLAD-TOH, K.; YEO, G. S. H.; O'RAHILLY, S. A Deletion in the Canine POMC Gene Is Associated with Weight and Appetite in Obesity-Prone Labrador Retriever Dogs. Cell Metabolism, v. 23, n. 5, p. 893-900, may, 2016.

RAMOS, A. M. P. P.; BARROS FILHO, A. de A. Prevalência da Obesidade em Adolescentes de Bragança Paulista e Sua Relação com a Obesidade dos Pais. Arq Bras Endocrinol Metab vol, v. 47, n. 6, p. 633-668, dezembro, 2003.

RAMOS, H. D.; PITANGA; F. J. G.; LESSA, I. Waist/Height Ratio Compared With Other Anthropometric Indicators Of Obesity As A Predictor Of High Coronary Risk. Rev Assoc Med Bras, v. 56, n. 6, p. 705-711, nov-dec., 2010.

ReZende, F. A. C.; ROSADO, L. E. F. P. L.; FRANCESCHINNI, S. do C. C.; ROSADO, G. P.; RIBEIRO, R. de C. L. The body mass index applicability in the body fat assessmentien. Rev. bras. med. esporte, v. 16, n. 2, p. 90-94, jan., 2010.

ROBERTSON, I. D. The Association of Exercise, Diet and Other Factors with OwnerPerceived Obesity in Privately Owned Dogs from Metropolitan Perth, WA. Preventive veterinary medicine, v. 58, n. 1-2, p. 75-83, april, 2003.

ROUDEBUSH, P.; SCHOENHERR, W. D.; DELANEY, S. J. Timely topics in nutrition - An evidence-based review of the use of nutraceuticals and dietary supplementation for the management of obese and overweight pets. Javma- Journal Of The American Veterinary Medical Association, v. 232, n. 11, p. 1646-1655, jun., 2008. 
RYAN, V. H.; GERMAN, A. J.; WOOD, I. S.; HUNTER, L.; MORRIS, P.; TRAYHURN, P. Adipokine Expression and Secretion by Canine Adipocytes: Stimulation of Inflammatory Adipokine Production by LPS and TNFa. Pflugers Archiv European Journal of Physiology, v. 460, n. 3, p. 603-616, aug., 2010.

ROYAL CANIN. Telephone survey on canine obesity with $\mathbf{4 0 0}$ veterinarians from France, Germany, Spain and UK. May-July. 2000. Dados não publicados. In: DIEZ, M.; NGUYEN, P. Capítulo 1. Obesity. Encyclopedia of Canine Clinical Nutrition. (United States) 4 ed., p.5, 2006.

MICHEL, K. E. Nutritional management of body weight. In: FASCETTI, A. J.; DELANEY, S. J. editors. Apllied veterinary clinical nutrition. Chichester (United Kingdom): Wiley-Blackwell, 109-124, 2012.

SALMERI, K. R.; OLSON, P. N.; BLOOMBERG, M. S. Elective Gonadectomy in Dogs: A Review. Journal of the American Veterinary Medical Association, v. 198, n. 7, p. 1183-1192, april, 1991.

SELLTIZ, C.; WRIGHTSMAN, L.S.; COOK, S. W. Research Methods in Social Relations. New York: Rinehart and Winston, 4. ed., 1981. 622 p.

SENEVIRATNE, M.; SUBASINGHE, D. W. D.; WATSON, P. J. A survey of pet feeding practices of dog owners visiting a veterinary practice in Colombo, Sri Lanka. VETERINARY MEDICINE AND SCIENCE, v. 2, n. 2, p. 106-116, feb., 2016.

SÖDER, J.; WERNERSSON, S.; HAGMAN, R.; KARLSSON, I.; MALMLÖF, K.; HÖGLUND, K. Metabolic and Hormonal Response to a Feed-Challenge Test in Lean and Overweight Dogs. Journal of Veterinary Internal Medicine, v. 30, n. 2, p. 574582, march-april, 2016. 
SPAIN, C. V.; SCARLETT, J. M.; HOUPT, K. A. Long-Term Risks and Benefits of Early-Age Gonadectomy in Dogs. Journal of the American Veterinary Medical Association, v. 224, n. 3, p. 380-387, feb., 2004.

TEIXEIRA, F. A.; SANTOS, J. P. F.; DUARTE, C. N.; HALFEN, D.; NOGUEIRA, J. S.; BRUNETTO, M. A. The body condition score percepetion differs between dogs and cats owners. Journal of Animal Physiology and Animal Nutrition, v. 99, n. 5, p. 99, april, 2015.

TENORIO, A. S.; COBAYASHI, F. Perception of childhood obesity by parents. Rev Paul Pediatr., v. 29, n. 4, p.634-639, jan., 2011.

THES, M.; KOEBER, N.; FRITZ, J.; WENDEL, F.; DILLITZER,N.; DOBENECKER, B.; KIENZLE, E. Metabolizable energy intake of client-owned adult dogs. Journal of Animal Physiology and Animal Nutrition, v. 100, p. 813-819, 2016.

TOLL, P. W.; YAMKA, R. M.; SCHOENHERR, W. D.; HAND, M. S. Obesity. In: HAND, M. S.; THATCHER, C. D.; REMILLARD, R. L.; ROUDEBUSH, P.; NOVOTNY, B. J. (Ed.). Small Animal Clinical Nutritional. 5. ed. Topeka, Kansas: Mark Morris Institute, 2010. p. 501-542.

THRUSFIELD, M. Veterinary Epidemiology. 3. ed. Oxford: Blackwell Science, 2007. $626 \mathrm{p}$.

TVARIJONAVICIUTE, A.; CERON, J. J.; HOLDEN, S. L.; CUTHBERTSON, D. J.; BIOURGE, V.; MORRIS, P. J.; GERMAN, A. J. Obesity-related metabolic dysfunction in dogs: a comparison with human metabolic syndrome. BMC veterinary research, v. 8 , n. 1, p. 1-8, agust, 2012. 
USUI, S.; YASUDA, H.; KOKETSU, Y. Characteristics of Obese or Overweight Dogs Visiting Private Japanese Veterinary Clinics. Asian Pacific Journal of Tropical Biomedicine, v. 6, n. 4, p. 338-343, april, 2016.

WEETH, L. P.; FASCETTI, A. J.; KASS, P. H.; SUTER, S. E.; SANTOS, A. M.; DELANEY, S. J. Prevalence of Obese Dogs in a Population of Dogs with Cancer. American journal of veterinary research, v. 68, n. 4, p. 389-398, apr., 2006.

VELÁSQUEZ-MELÉNDEZ, G.; PIMENTA, A. M.; KAC, G. Epidemiologia do sobrepeso e da obesidade e seus fatores determinantes em Belo Horizonte (MG), Brasil: estudo transversal de base populacional. Revista Panamericana de Salud Pública, v. 16, n. 5, p. 308-314, 2004.

VENDRAMINI, T. H. A. Expressão gênica da resposta imunoinflamatória e status imunológico de cães obesos e emagrecidos. 2019. $100 \mathrm{f}$. Tese de Doutorado (Doutorado em Ciências) - Faculdade de Medicina Veterinária e Zootecnia, Universidade de São Paulo, São Paulo, 2019.

WITZEL, A. L.; KIRK, C. A.; HENRY, G. A.; TOLL, P. W.; BREJDA, J. J.; PAETAUROBINSON, I. Use of a morphometric method and body fat index system for estimation of body composition in overweight and obese cats. Javma-Journal of The American Veterinary Medical Association, v. 244, n. 11, p. 1285-1290, jun., 2014.

WOHLFARTH, R.; MUTSCHLER, B.; BEETZ, A.; KREUSER, F.; KORSTEN-RECK, U. Dogs Motivate Obese Children for Physical Activity: Key Elements of a Motivational Theory of Animal-Assisted Interventions. Frontiers in psychology, v. 4, p. 796 , oct., 2013. 
ZORAN, D. L. Obesity in Dogs and Cats: A Metabolic and Endocrine Disorder. The Veterinary clinics of North America. Small animal practice, v. 40, n. 2, p. 221239, mar., 2010. 


\section{APÊNDICES}


APÊNDICE A - Quadro da resenha, informações sanitárias, doenças e características do manejo nutricional dos cães foi realizada a anamnese

\begin{tabular}{|c|c|c|}
\hline Número do animal: & $\begin{array}{l}\text { Número do domicílio: } \\
\text { Casa( ) Apê ( ) }\end{array}$ & Número do Setor: \\
\hline 1-Nome do cão: & 2-Idade: & 3-Sexo: \\
\hline 4- Raça: & & 5-Doença: \\
\hline 6- Castrado: ( ) Sim & 7- Idade de castração: & 8-Vacinas: ( ) Sim \\
\hline $\begin{array}{l}8.1 \text {-Vacinas: ( ) anual } \\
\text { ( )atrasadas } \\
\text { ( ) Nunca }\end{array}$ & $\begin{array}{r}\text { 8.2-Campanha: ( ) Sim } \\
\text { ( )Não }\end{array}$ & $\begin{array}{r}8.3 \text { Veterinário: ( ) Sim } \\
\text { ( )Não }\end{array}$ \\
\hline $\begin{array}{l}\text { 9- Visitas no veterinário: } \\
\text { ( ) Sim } \\
\text { ( )Não }\end{array}$ & $\begin{array}{l}\text { 9.1- Frequência: } \\
\text { ( ) } 3-3 m \\
\text { ( ) } 6-6 m \\
\text { ( ) anual } \\
\text { ( ) só quando fica doente } \\
\text { ( )nunca }\end{array}$ & \\
\hline $\begin{array}{l}\text { 10- Alimento: } \\
\text { ( ) Ração } \\
\text { ( ) Comida caseira prescrita } \\
\text { ( )Resto de comida } \\
\text { ( )Ração+ comida } \\
\text { ( ) Outros }\end{array}$ & $\begin{array}{l}\text { 10.1 -Frequência: } \\
\text { ( )À vontade } \\
\text { ( ) } 2 x / \text { dia } \\
\text { ( ) } 3 x / \text { dia } \\
\text { ( ) } 4 x \text { ou mais/dia }\end{array}$ & $\begin{array}{l}\text { 10.2- Quantidade: } \\
\text { ( ) Medida inespecífica } \\
\text { ( )Livre } \\
\text { ( ) Pesada }\end{array}$ \\
\hline $\begin{array}{l}\text { 11- Qual foi critério para } \\
\text { determinar a quantidade: } \\
\text { ( ) Rótulo } \\
\text { ( ) Veterinário } \\
\text { ( ) Balconista } \\
\text { ( ) Não foi determinada }\end{array}$ & $\begin{array}{l}\text { 11.1- Nome da ração: } \\
\text { 11.2-Petisco: }\end{array}$ & $\begin{array}{l}\text { 12-Exercício: } \\
\text { 13-Animais na casa= }\end{array}$ \\
\hline
\end{tabular}



1 - Idade
a) Entre 18 e 24 anos
b) Entre 25 e 34 anos
c) Entre 35 e 44 anos
d) Entre 45 e 59 anos
e) Entre 60 e 75 anos
f) Acima de 76 anos

\section{2- Sexo \\ a) Masculino \\ b) Feminino}

\section{3- A casa onde você mora é?}

a) Própria

b) Alugada

c) Cedida

\section{4- Escolaridade}

a) Da $1^{\text {a }}$ à $4^{\underline{a}}$ série do Ensino Fundamental (antigo primário)

b)Da $5^{\text {a }}$ à $8^{\text {a }}$ série do Ensino Fundamental (antigo ginásio)

c) Ensino Médio (antigo $2^{\circ}$ grau)

d) Ensino Superior

e) Especialização

(F) Não estudou

5 - Somando a sua renda com a renda das pessoas que moram com você, quanto é, aproximadamente, a renda familiar mensal? (Marque apenas uma resposta)

a) Nenhuma renda.

b) Até $R \$ 324$

c) $\mathrm{De} R \$ 648,00$ até $R \$ R \$ 1.164$ d) $\mathrm{De} R \$ 1.165$ a $\mathrm{R} \$ 4.076$

e) $\mathrm{De} R \$ 4.077$ a $R \$ 9.920$

f) ACIMA R $\$ 9.921$

\section{6- Em que você trabalha atualmente?}

a) Governo (Setor Público)

b) Empresa (privada ou estatal)

c) ONG

d) Conta própria

e) Propriedade Rural

f) Desempregado

g)Aposentado

h)Do lar

i)Estudante

\section{7- Quantas horas semanais você} trabalha?

a) Sem jornada fixa, até 10 horas semanais.

b) De 11 a 30 horas semanais

c) De 30 a 40 horas semanais.

d) $>40$ horas semanais.

\section{8- Qual meio de transporte utiliza:}

a) Transporte público (Metrô/ Trem/ Ônibus)

b) Carro próprio

c) Moto

d) A pé

e) Transporte Privado (Taxi/Ubber)

9 - Número de pessoas que moram na residência e idade

a)Entre 0 e 12 anos
b) Entre 13 e 18 anos
c) Entre 19 e 24 anos
d) Entre 25 e 34 anos
e) Entre 35 e 44 anos
f) Entre 45 e 59 anos
g) Entre 60 e 75 anos
h) Acima de 76 anos

10 - Dê uma nota para a vida social:

a) $0=$ não sai e/ou visita amigos

b) 1 = semanalmente

c) 2 = quinzenalmente

d) $3=$ mensalmente

\section{1- Com que frequência recebe visitas em} casa
a) 2 vezes na semana
b) 1 vez na semana
c) A cada 15 dias
d) A cada 30 dias
e) A cada 60 dias
f) Em intervalos superiores a 61 dias

12 - Grau de atividade física do tutor

a) Diariamente

b) Uma vez por semana

c) Três vezes por semana

d) Mais que três vezes por semana

e) Não pratica

\section{3- Duração da pratica de atividade física}

Especifique a atividade física: 
14- Você acha que você come

( )Em excesso ( ) Normal ( )Pouco

15-Quantas vezes você consome alimentos na forma de frituras?
() Diariamente () 1-2 vezes por Semana
() Esporadicamente

$$
\text { ( ) Nunca }
$$
() +3x semana

16-.Qual a frequência que você consome frutas?

() Diariamente () 1-2 vezes por Semana () $+3 x$ semana

( ) Esporadicamente

() Nunca
17.Qual a frequência que você consome vegetais?

() Diariamente () 1-2 vezes por Semana

() $+3 x$ semana

( ) Esporadicamente

( ) Nunca

18.Qual a frequência que você consome guloseimas ?

() Diariamente () 1-2 vezes por Semana

( ) $+3 x$ semana

( ) Esporadicamente

( ) Nunca

19-Com relação ao peso do seu anima, você acha que seu cão

esta:

( ) Abaixo do peso

( ) Ideal

) Sobrepeso

( )Obeso 